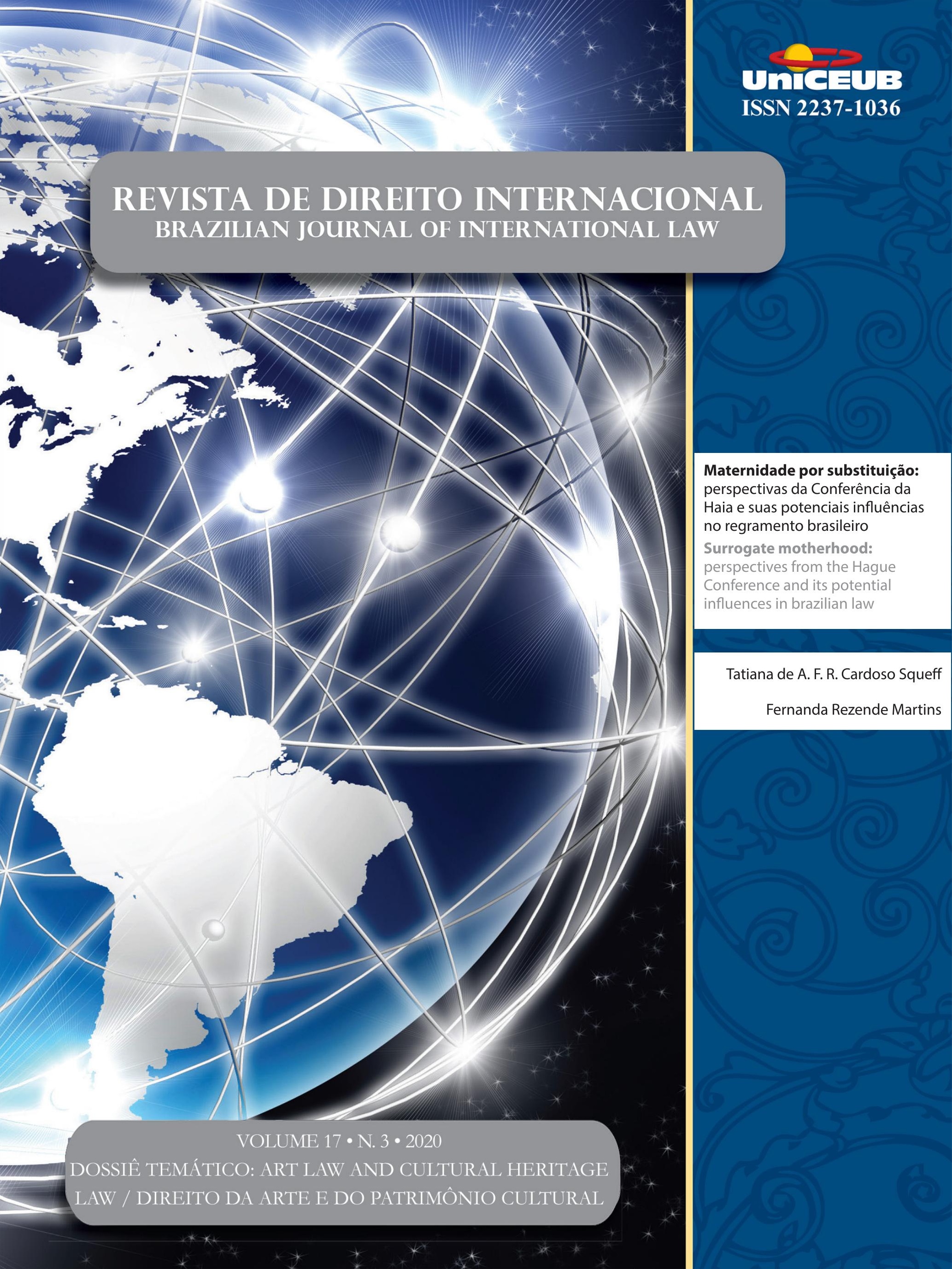




\section{Sumário}

EDITORIAL .20

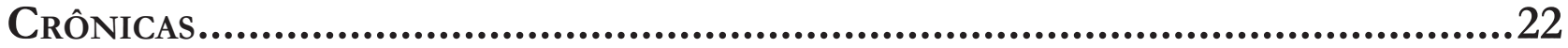

O COSTUME INTERNACIONAL COMO REFORÇO DA OBJEÇÃO BRASILEIRA À CLÁUSULA DO TRATAMENTO JUSTO E EQUITATIVO .24

Leonardo Vieira Arruda Achtschin

O PROCESSO LEGISLATIVO COMO GARANTIA PARA A OBTENÇÃo DO CONSENTIMENTO PRÉVIO DAS COMUnidades quilombolas de AlCÂNTARa

Gabriel de Oliveira Borba

Dossiê temático: Art Law and Cultural Heritage law / Direito da Arte e do Patrimônio cultural - Panorama Geral

Peoples' heritage or States' heritage? sovereignty in the UNESCO mechanism for THE SAFEGUARDING OF INTANGIBLE CULTURAL HERITAGE.

Aliki Gkana

The IMPACT OF THE UNESCO AND UNIDROIT CONVENTIONS AND THE EU DIRECTIVES ON THE INTERNATIONAL ART MARKET: AN ANALYSIS FIFTY YEARS AFTER THE INTRODUCTION OF THE OBLIGATION TO RETURN STOLEN OR ILLEGALLY EXPORTED CULTURAL GOODS 61

Geo Magri

Três pautas em destaque na agenda de diversidade Cultural da Unesco: Ambiente digiTAL, TRATAMENTO PREFERENCIAL E PARTICIPAÇÃO DA SOCIEDADE CIVIL............................76

Danilo Júnior de Oliveira, Maria Carolina Vasconcelos Oliveira e Ana Paula do Val

A 100 YEARS INSTITUTIONALIZED CULTURAL HERITAGE PROTECTION: FROM THE INSTITUTIONALIZED INTERNATIONAL COOPÉRATION INTELLECTUELLE TO THE HUMAN RIGHT TO CULTURAL HERITAGE

Lando Kirchmair 


\section{Aspectos Metodológicos do Direito da Arte e do Patrimônio}

Cultural

A proteção do PATrimônio CULTURAL EM NOVAS PERSPECTIVAS: ESTUdo COMPARAdo ENTRE A Kulturgutschutzgesetz e a Holocaust Expropriated Art Recovery Act of 2016.....111 Ardyllis Alves Soares

ArT-RELATED DispUTES AND ADR METHODS 127 Maria Beatrice Deli e Veronica Proietti

Due Diligence in Art Law and Cultural Heritage Law 150 Lisiane Feiten Wingert Ody

The Reception of Droit de Suite in International Law: Diagnosis and Remedy .... 170 Mickael R. Viglino

Direito da Arte e do Patrimônio Cultural: do Regional ao Local ....... 188

Câmara Cascudo e o legal Design - A Visualidade do Direito entre Provincianismo e GlobalizaÇão 190 Marcilio Toscano Franca Filho

A política da União Europeia no turismo: O turismo cultural e a sustentabilidade do PATRIMONNIO INDUSTRIAL PARA INTEGRAÇÃO DO BLOCO EUROPEU

Maraluce Maria Custódio e Fernando Barotti dos Santos

Diálogo entre la Corte Interamericana de Derechos Humanos y el Tribunal Europeo de Derechos Humanos en torno al Derecho humano a la identidad cultural..223 Juan Jorge Faundes

Digital ART AND THE BELT AND ROAD INITIATIVE: CHALLENGES AND OPPORTUNITIES 257 Dan Wei e Ângelo Rafael

Policing heritage crime in Latin America. .275 Naomi Oosterman e Donna Yates 
The principles of Cultural Heritage Law based on the Polish Law as an example.292 Małgorzata Joanna Węgrzak e Kamil Zeidler

Heritage Protection in INTERNATIONAL LAw AND NATIONAL LAW: INSIGHTS INTO THE CASE OF VIETNAM

Yen Thi Hong Nguyen e Dung Phuong Nguyen

THE APPROPRIATION OF THE CARIOCA INTANGIBLE CULTURAL HERITAGE BY AN ENTREPRENEURIAL LOGIC

Mário Ferreira de Pragmácio Telles

A Propósito del CARÁcter UNIVERSAL DEL aCCESO A LA CULTURA EN INTERNET: UN ANÁlisis DESDE EL PRISMA INTERNACIONAL Y LA EXPERIENCIA DEL ORDENAMIENTO JURÍDICO CUBANO 344 Janny Carrasco Medina

Direito Humanitário e Arte

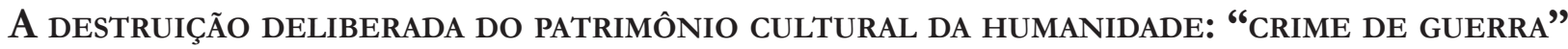
OU "CRIME CONTRA A HUMANIDADE"? Juliette Robichez

Protection OF CULTURAL PROPERTY UNDER INTERNATIONAL HUMANITARIAN LAW: EMERGING TRENDS

Niteesh Kumar Upadhyay e Mahak Rathee

Direito do Mar/Marítimo e Arte.

The underwater Cultural heritage Regime: SOME PROBlems AND POSSible SOlutions. 412 Elina Moustaira

El ROL DEL DERECHO EN LA CONSTRUCCIÓN DEL PATRIMONIO CULTURAL SUBACUÁTICO: APRECiaciones a partirdel estudio del CASo de la Corbeta Inglesa SwifT en Argentina .. 424 Norma Elizabeth Levrand e Nadia Bressan Bernhardt 
INDIGENOUS REFUGEES AND CULTURAL EROSION: POSSIBILITIES AND LIMITS OF INTERNATIONAL REFUGEE AND INDIGENOUS PEOPLES LAW IN THE PROTECTION OF INDIGENOUS CULTURAL EXPRESSIONS RELATED TO TRADITIONAL LAND AND NATIVE LANGUAGE. .440 Rickson Rios Figueira

O RETRATO DE EDMOND BELAMY E A INTERFACE ENTRE ARTE E INTELIGENCIA ARTIFICIAL: POR UMA NOVA DEFINIÇÃo DE AUTORIA E DIREITOS DE PROPRIEDADE INTELECTUAL

Marla Meneses do Amaral Leite Mangiolardo, Patrícia Silva de Almeida e Jonathan Barros Vita

Argumentative aspects of Declaration on the Importance and Value of Universal Museums (2002) 479

Agnieszka Plata

A DestinaÇão dos bens CUlturais EM PROCESSOS PENAIS: A ARTE COMO REPARAÇÃo COLETIVA 488

Inês Virgínia Prado Soares e Otavio Venturini

A Justiça de Pieter Bruegel: direito, violência e a venda nos (nossos) olhos. .501 Rafael Lazzarotto Simioni e Cícero Krupp

Artigos Sobre outros temas

DEVERES INTERNACIONAIS E OBRIGAÇÕES SOCIOAMBIENTAIS PARA EMPRESAS MULTI E TRANSNACIONAIS

Luísa Cortat Simonetti Gonçalves e Adriano Sant'Ana Pedra

Maternidade por substituição: perspectivas da ConferênCia da Haia e suas potenciais INFLUÊNCIAS NO REGRAMENTO BRASILEIRO

Tatiana de A. F. R. Cardoso Squeff e Fernanda Rezende Martins

EL (LARGO) CAMINO DE RECONOCIMIENTO Y EJECUCIÓN DE LAUDOS ARBITRALES DE INVERSIÓN

Thiago Paluma, Ivette Esis e Gabriel Briceño 
A INTERPRETAÇÃo EVOLUTIVA DA CONVENÇÃo AMERICANA SOBRE DiREITOS HUMANOS: UMA REVISÃO DOCUMENTAL DO PERÍODO 1988-2018

Breno Baía Magalhães

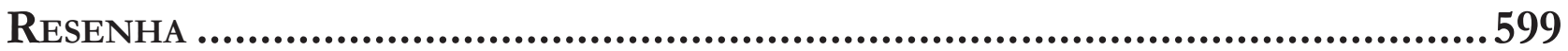

Autonomous Weapons Systems and InTERnATIONAL LAw: A STUDY ON HUMAN-MACHINE INTERACTIONS IN ETHICALLY AND LEGALLY SENSITIVE DOMAINS

Aziz Tuffi Saliba e Lutiana Valadares Fernandes Barbosa 


\title{
Maternidade por substituição: perspectivas da Conferência da Haia e suas potenciais influências no regramento brasileiro*
}

\author{
Surrogate motherhood: perspectives from the \\ Hague Conference and its potential influences \\ in brazilian law
}

Tatiana de A. F. R. Cardoso Squeff**

Fernanda Rezende Martins***

\section{Resumo}

O desenvolvimento tecnológico propiciou a criação e aperfeiçoamento de técnicas de reprodução medicamente assistidas, entre elas a gestação por substituição. Caracterizada pelo fato de uma mulher que não pretende assumir a maternidade ceder seu corpo para gestar uma criança para outrem, a técnica, ainda, carece de diálogo, controle e regulamentação no Brasil e em âmbito internacional. Logo, o presente artigo tem como objetivo observar como as discussões em curso na Conferência de Direito Internacional Privado da Haia $(\mathrm{HCCH})$ podem influenciar a forma como o Brasil trata o assunto. Afinal, no âmbito do Direito Internacional Privado, ainda não há tratado internacional sobre o tema, forte nas divergentes posições entre os países. Assim, utilizando-se do método dedutivo de abordagem e, segundo os modelos descritivo e explicativo de análise dos objetivos, este artigo destaca os efeitos da tecnologia na maternidade, a variedade de abordagens sobre o tema no mundo, incluindo o Brasil, e como a $\mathrm{HCCH}$ vem se posicionando a respeito do assunto. Para tanto, consultam-se a doutrina nacional e estrangeira sobre o tema, e os principais documentos já editados sobre o assunto, em especial, do Conselho Federal de Medicina e da HCCH. Por fim, os resultados apontam que os diálogos, até então realizados, estão fornecendo princípios básicos e consolidando regras de caráter de soft law. Logo, a busca por um instrumento multilateral pode instigar o Brasil, que ainda não possui regulamentação própria, a discutir e se posicionar para que os direitos basilares de todos os envolvidos na gestação por substituição sejam preservados.

Palavras-chave: Conferência de Direito Internacional Privado da Haia. Gestação por substituição. Maternidade. Sub-rogação.

*** Mestranda na Universidade Federal de Uberlândia, na Linha de Pesquisa: "Sociedade, Sustentabilidade e Direitos Fundamentais" (2019-2021). Especialista em Direito Ambiental e Urbanístico pela PUC-Minas. Graduada em Direito pela Universidade Federal de Uberlândia.

E-mail: fernandarm@hotmail.com

PPGD) e em Língua Inglesa (Unilasalle). E-mail: tatiafrcardoso@gmail.com

** Professora permanente do Programa de eral de Uberlândia (UFU), onde também é professora adjunta na Graduação. Doutora em Disanduíche junto à University of Ottawa. Mesbolsa capes e perodo de estudos junto à versity of Toronto, com fomento DFAIT. Especialista em Relações Internacionais (UFRGS/ PPGEEI), em Direito Internacional (UFRGS/

\section{Abstract}

Technological development led to the creation and improvement of medically assisted reproductive techniques, including surrogate maternity. It is characterized by the fact that a woman who does not intend to assume motherhood gives her body to give birth to another child, the technique 
still lacks debate, control and regulation in Brazil and around the globe. Therefore, this article aims to observe how the ongoing discussions at the Hague Conference on Private International Law (HCCH) could influence the way Brazil deals with the subject. After all, under the Private International Law, there is not yet an international treaty on the subject, due to the divergent positions of nations worldwide. Thus, using the deductive method of approach and in accordance with the descriptive and explanatory models of object analysis, this research highlights the effects of technology on maternity, the variety of approaches on the subject in the world, including Brazil, and how the HCCH has been positioning itself over it. For this end, foreign and domestic doctrine over the subject are analyzed, just as the main documents enacted over this topic, especially those by the Brazilian Medical Federal Council and HCCH. At the end, the results show that the debates previously conducted are providing basic principles and consolidating soft laws. Thus, the search for a multilateral instrument may prompt Brazil, which does not yet have its own regulation, to discuss and position itself so that the fundamental rights of all those involved in substitution pregnancies are preserved.

Keywords: Hague Conference on Private International Law. Surrogate motherhood. Motherhood. Surrogacy.

\section{Introdução}

A criação e o aperfeiçoamento das técnicas de reprodução medicamente assistida obtiveram um importante papel para a remodelagem do corpo familiar. Definir e fazer com que sejam reconhecidas a maternidade, a paternidade, a filiação e a composição de uma família atualmente esbarram em premissas não mais adequadas. A pós-modernidade, assim, coloca em xeque conceitos tradicionais e basilares frente ao desenvolvimento tecnológico e aos novos anseios sociais.

Dentre as diversas técnicas desenvolvidas, a gestação por substituição, também chamada de maternidade por sub-rogação ou substituição, é uma alternativa em alta entre aqueles que buscam realizar o sonho da maternidade/paternidade. Apesar de cada vez mais preterida em detrimento do procedimento de adoção, a gestação não é objeto de nenhum documento internacional que harmonize questões de contratação da técnica de reprodução em situações que envolvam mais de um país.

Desse modo, presencia-se uma variedade de tratamentos quanto à temática, que vão desde sua expressa proibição, possibilidade do uso da técnica de forma comercial até mesmo a falta de regulamentação, como é o caso do Brasil. A ausência de regulação nacional, bem como a de um instrumento multilateral, pode deixar vulneráveis os direitos fundamentais básicos do bebê oriundo da gestação, da mãe substituta e dos pretensos pais. Apenas o diálogo entre nações no âmbito do Direito Internacional Privado pode garantir que os procedimentos de gestação por substituição garantam a dignidade da pessoa humana a todos os envolvidos.

Por essa razão, o presente artigo analisa como as discussões em curso na Conferência da Haia podem influenciar a forma com que o Brasil trata a temática da maternidade por substituição. Tal investigação no Direito Internacional Privado se justifica em razão dos conflitos e lides propostas para o reconhecimento da nacionalidade de crianças oriundas dos procedimentos de maternidade substitutiva, haja vista que cada país legisla de acordo com a sua realidade nacional.

Para tanto, por meio do método dedutivo de abordagem, o presente texto divide-se em duas partes, as quais desenvolvem-se com base nas técnicas documental e bibliográfica de pesquisa, selecionadas qualitativamente desde o objetivo geral de pesquisa. Assim, na primeira parte, segundo os modelos descritivo e explicativo, aponta-se os efeitos produzidos pela evolução das técnicas medicamente assistidas sobre a maternidade, além de apresentar um panorama quanto ao tratamento do uso dessa técnica em países selecionados, incluindo-se o Brasil, consultando-se não apenas a doutrina nacional e estrangeira sobre o tema, como também os principais documentos já editados sobre o assunto, especialmente do Conselho Federal de Medicina, sem o condão, porém, de esgotá-los. Já na segunda parte, de maneira analítica, discorre-se sobre os desafios enfrentados por aqueles que buscam contratar a gestação por substituição ou fazer parte do procedimento, bem como os posicionamentos da Conferência de Direito Internacional Privado da Haia $(\mathrm{HCCH})$ e suas possíveis influências no tratamento brasileiro acerca do tema, examinando-se, para tal fim, não apenas a doutrina nacional e estrangeira sobre o tema, como também os principais documentos emanados da HCCH. 


\section{0 contexto atual da maternidade por substituição no Brasil e no exterior}

As técnicas de reprodução assistida estão cada vez rotineiras na pós-modernidade ${ }^{1}$, haja vista a constante reconfiguração de ideais perseguidos pelo homem. Dessa forma, realizar o sonho da maternidade ou paternidade não se restringe mais, apenas, a formas convencionais de reprodução. A maternidade por substituição, enfoque deste artigo, é uma das técnicas em que a geração de uma criança pode envolver mais de duas pessoas, constatando o desenvolvimento médico na seara da reprodução na sociedade atual.

As consequências oriundas dessa prática se mostram pouco conhecidas, principalmente ao se considerar o direito comparado e os variados sistemas de abordagem sobre o tema no mundo. Desse modo, conhecer o panorama da gestação por substituição mostra-se essencial para compreender a complexidade da temática e as implicações jurídicas que esta pode causar no embate entre realidades diferentes ao redor do globo.

\subsection{As técnicas de reprodução "medicamente' assistidas e os efeitos desta sobre a maternidade}

$\mathrm{Na}$ atualidade, o novo redimensionamento social vem transformando a composição familiar em diversos aspectos. A emancipação da mulher e sua entrada no âmbito do trabalho, a afirmação e conquista de espaço das relações homoafetivas, bem como a consolidação da ideia de maternidade/paternidade sem a necessária presença de um(a) companheiro(a) convergiram em um mesmo ideal: o desejo de escolher quando e como ter filhos, independentemente das barreiras físicas impostas em cada uma das situações.

Nesse sentido, as técnicas de reprodução medicamente assistida ${ }^{2}$ ocorrerão

\footnotetext{
Sobre o cenário introduzido pela pós-modernidade, em especial pelo impacto do biopoder na otimização da vida. ZENNI, Alessandro Severino V. Os "ruídos" da ciência e o retorno ao direito clássico: única via à dignidade da pessoa humana. Universitas Jus, Brasília, v. 27, n. 3, p. 128-144, 2016. p. 133-135.

2 Para melhor compreensão, observa-se que essas técnicas de reprodução podem ser classificadas em: a) intracorpóreas: método por meio do qual a fecundação ocorre no interior do corpo da mulher, no qual é inserido o gameta masculino no aparelho genital
}

sempre que houver qualquer tipo de interferência médica para viabilizar ou facilitar a procriação, não abrangendo tão somente os procedimentos de inseminação artificial ou fertilização in vitro (e suas variações), mas também outros métodos nos quais há a relação sexual, como a administração de medicamentos para estimular a ovulação. ${ }^{3}$

Com isso, percebe-se que a busca por uma forma não convencional de reprodução não se limita, apenas, a casais estéreis ou com problemas de fertilidade. Hoje, as técnicas de reprodução são utilizadas em diversas demandas, seja de casais homoafetivos ${ }^{4}$, pessoas solteiras ou casais com idade mais avançada que decidam ter filhos. Tal estágio atual de medicalização da procriação marca, de acordo com Sandel ${ }^{5}$, o rompimento entre reprodução humana e sexualidade.

Discutir essa temática no âmbito do Direito se torna importante a partir do momento em que o evento que tradicionalmente definia legalmente a maternidade, isto é, o parto, não mais se amolda a todos os casos. As biotecnologias passaram a alterar papéis, permitindo identificar a gestante como mãe biológica, a doadora do material como mãe genética e, ainda, a autora do projeto de maternidade como mãe afetiva.

Esse fenômeno é chamado [...] de maternidade cindida ou split motherhood. Dessa forma, o conceito de que a maternidade não é mais uma, na medida em que há possibilidade de ter até três pretensões de maternidade: uma ancorada na gestação, outra

feminino tal como a inseminação artificial; b) extracorpóreas: tratase da fertilização in vitro (FIV), procedimento em que o óvulo e o espermatozoide são fecundados fora do corpo da mulher, em um tubo de ensaio ou mídia de cultivo, para, posteriormente, o óvulo fecundado ser transferido para o útero; c) homólogas: quando é utilizado o material genético (óvulo e espermatozoide) do próprio casal; e d) heterólogas: quando é utilizado o material genético de doadores, seja o óvulo, o espermatozoide ou ambos. DEL'OLMO, Florisbal de Souza. Barriga de aluguel no exterior e a aquisição da nacionalidade brasileira. Revista Brasileira de Direito Animal, Salvador, v. 11, n. 22, p. 177- 200, 2016. p. 180.

3 SOUZA, Marise Cunha de. As técnicas de reprodução assistida: a barriga de aluguel: a definição da maternidade e paternidade: bioética. Revista da EMERJ, Rio de Janeiro, v. 13, n. 50, 2010. p. 350.

4 STARK, Barbara. Transnational surrogacy and international human rights law: transnational surrogacy and international human rights law. ILSA Journal of International \& Comparative Law, v. 18, n. 2, p. 369-386, 2011-2012.

SANDEL, Michael J. Contra a perfeição: ética na era da engenharia genética. Rio de Janeiro: Civilização Brasileira, 2013. p. 34. 
na origem genética e outra, ainda, no projeto parental. ${ }^{6-7}$

Tal situação pode ser mais bem observada na gestação por substituição, caracterizada quando uma mulher que não pretende assumir a maternidade cede seu corpo para gestar uma criança para outrem ${ }^{8}$. Essa técnica é conhecida por diversas denominações, tais como útero de empréstimo, útero de aluguel, gestação por substituição, gestação sub-rogada, mãe sub-rogada, mãe de empréstimo, mãe substituta, mãe hospedeira, mãe por procuração, barriga de aluguel, cessão temporária de útero, dentre outras tantas que a identificam. ${ }^{?}$

Apesar de o termo adequado, ainda, ser discutido e suas consequências pouco conhecidas, o aumento na busca por essa alternativa para se ter filhos é notório. Araújo, Vargas e Martel $^{10}$ afirmam que o crescimento dos casos internacionais de gestação por substituição

\footnotetext{
ARAUJO, Nadia de; VARGAS, Daniela Trejos; MARTEL, Letícia de Campos Velho. A gestação de substituição: regramento no direito brasileiro e seus aspectos de direito internacional privado. In: BAPTISTA, Luiz Olavo; RAMINA, Larissa; FRIEDRICH, Tatyana Scheila (coord.). Direito Internacional Contemporâneo. Curitiba: Juruá, 2014. p. 499. Disponível em: http://nadiadearaujo. com/wpcontent/uploads/2015/03/GESTA \%C3\%87\%C3\%83odesubstitui $\%$ c3\%87\%c3\%83o-regramento-no-direito-brasileiro-eseus-aspectos-de-direitointernacional-privado.pdf. Acesso em: 20 jun. 2019.
}

Acerca dessa nova visão de maternidade, Swennen vai além, expondo quatro grandes desenvolvimentos que motivariam tal divisão: (a) a bifurcação entre a maternidade biológica e a genética; (b) a evolução da maternidade genética, englobando doações que vão além de óvulo (egg cell), mas de mitocôndria (mitochondrial); (c) a intenção legal de maternidade, englobando casais homoafetivos; e (d) a maternidade social, sobre o desenvolvimento de vínculos afetivos que não necessariamente derivam de um status parental. SWENNEN, Frederik. Motherhoods and the Law. In: WILLEKENS, Harry et al. (ed.). Motherhoods and the Law. Göttingen: Universitätsverlag Göttingen, 2019. p. 101-118. p. 103-105.

8 CERVI, Taciana Damo; CAMERA, Sinara. Os reflexos da Conferência de Haia sobre direito internacional privado em relação à nacionalidade decorrente da maternidade por substituição transnacional. Revista da Faculdade de Direito UFPR, Curitiba, v. 62, n. 3, p. 81-101, set./dez. 2017.

9 SILVA, Flávia Alessandra Naves. Gestação por substituição: direito a ter um filho. Revista de Ciências Jurídicas e Sociais. Guarulhos, v. 1, n. 1 , p. 50-67, 2011.

10 ARAUJO, Nadia de; VARGAS, Daniela Trejos; MARTEL, Letícia de Campos Velho. A gestação de substituição: regramento no direito brasileiro e seus aspectos de direito internacional privado. In: BAPTISTA, Luiz Olavo; RAMINA, Larissa; FRIEDRICH, Tatyana Scheila (coord.). Direito Internacional Contemporâneo. Curitiba: Juruá, 2014. p. 482. Disponível em: http://nadiadearaujo.com/ wpcontent/uploads/2015/03/GESTA $\%$ C3\%87\%C3\%83o-de substitui $\%$ c 3\%87\%c3\%83o-regramento-no-direito-brasileiro-eseus-aspectos-de-direitointernacional-privado.pdf. Acesso em: 20 jun. 2019 está diretamente ligado à maior rigidez na concessão de adoções internacionais, principalmente após a regulamentação da Conferência da Haia. As possibilidades de se proceder a uma adoção internacional diminuíram com os novos sistemas de proteção legal, além de serem procedimentos longos e custosos. ${ }^{11}$ Nesse cenário, a maternidade por substituição aparece como uma alternativa mais rápida e simples à adoção ${ }^{12}$, e com a vantagem de que a criança pode ser geneticamente ligada aos autores do projeto parental.

Inserida no contexto da pós-modernidade, em que as incertezas e a falta de segurança assomam diversos âmbitos da vida social, Martinho lembra que "a procriação artificial coloca questões que ultrapassam o campo da terapêutica e da ciência que as fez nascer. Põem em causa o estado das pessoas, as estruturas familiares e as liberdades individuais do ser humano". ${ }^{13}$ Dessa forma, os inúmeros desdobramentos jurídicos que podem advir do uso dessa técnica, seja na sua forma gratuita ou onerosa, tornam-se, ainda, mais complexos ao analisar as diferentes formas com que a temática é tratada no mundo.

\subsection{A gestação por substituição no âmbito global}

Quando a temática da maternidade por substituição é vista por um âmbito global, é comum encontrar classificações que agrupam o uso da técnica em três siste-

11 "There has been a resistance to likening surrogacy to adoption in part because the restrictions on inter-country adoption often resulted in discrimination against LGBT parents, single parents, and parents that did not otherwise fit the mold of the ideal adoptive parents. [...] [B] oth adoption and surrogacy target the same market. [...] [L]ittle regulation exists in the surrogacy context. However, adoption is highly regulated'. MOHAPATRA, Seema. Adopting an international convention on surrogacy: a lesson from intercountry adoption. Loyola University Chicago International Law Review, v. 13, n. 1, p. 24-55, 2015. p. 37-38.

12 Essa afirmativa não pode ser generalizada, porquanto ela depende de vários fatores. Engel, por exemplo, defende justamente o oposto, tecendo que a maternidade por substituição é "anything but quick and easy" no contexto europeu, pois, "[i]n the vast majority of jurisdictions, motherbood is initially attached to the woman who carried the child. Furthermore, many surrogate mothers are married, which makes the laws of most countries presume her husband to be the father. This impedes the child in getting the same passport as his intended parents who thus have to challenge the parenthood of the surrogate or her husband'. ENGEL, Martin. Crossborder surrogacy: time for a convention? In: BOELE-WOELKI, Katharina et al. Family law and culture in Europe: developments, challenges and opportunities. Cambridge: CUP, 2014. p. 199-216. p. 205. 13 SILVA, Paula Martinho da. A procriação artificial: aspectos jurídicos. Lisboa, Portugal: Moraes, 1986. p.107. 
mas diversos ${ }^{14}$. Os países do primeiro grupo são aqueles que permitem a gestação por substituição sem ou com poucas restrições, inclusive em contratos comerciais, denominados barriga de aluguel. Algumas províncias do Canadá, Reino Unido, Ucrânia e Holanda são exemplos de países nessa classificação. Já no segundo grupo estão os países que proíbem, expressamente, a prática em qualquer condição, sendo a Alemanha e a Espanha exemplos dessa condição. Por último, há países que permitem, de forma bastante restritiva, como é o caso do Brasil, Argentina e Chile. ${ }^{15}$

Não obstante, a classificação descrita representa, apenas, um panorama quase simplista da forma como a gestação por substituição é abordada no mundo. A realidade relativa a cada agrupamento é mais complexa. Em cada país é possível encontrar uma peculiaridade. É adequado, portanto, atentar-se para as disparidades que podem existir em uma mesma classificação, considerando-se fatores políticos, culturais ou históricos que influenciam cada país.

Nessa perspectiva, com base na primeira classificação, países que permitem a gestação por substituição sem ou com poucas restrições, inclusive em seu aspecto comercial, é possível perceber a diferença de abordagem entre o Canadá, Israel e Ucrânia, apesar de inseridos no mesmo grupo. No Canadá, por exemplo, o casamento entre pessoas do mesmo sexo é legalizado, além de ser permitida a adoção, reprodução medicamente assistida e a maternidade por substituição por pessoas

14 ARAUJO, Nadia de; VARGAS, Daniela Trejos; MARTEL, Letícia de Campos Velho. A gestação de substituição: regramento no direito brasileiro e seus aspectos de direito internacional privado. In: BAPTISTA, Luiz Olavo; RAMINA, Larissa; FRIEDRICH, Tatyana Scheila (coord.). Direito Internacional Contemporâneo. Curitiba: Juruá, 2014. p. 501-502. Disponível em: http://nadiadearaujo. com/wpcontent/uploads/2015/03/GESTA \%C3\%87\%C3\%83ode substitui $\%$ c3\%87\%c3\%83o-regramento-no-direito-brasileiro-eseus-aspectos-de-direitointernacional-privado.pdf. Acesso em: 20 jun. 2019; CERVI, Taciana Damo; CAMERA, Sinara. Os reflexos da Conferência de Haia sobre direito internacional privado em relação à nacionalidade decorrente da maternidade por substituição transnacional. Revista da Faculdade de Direito UFPR, Curitiba, v. 62, n. 3, p. 81-101, set./dez. 2017.

15 ARMOUR, Kim L. Surrogacy Around the World: trends, questions and ethical issues. Nursing for Women's Health, v. 16, n. 3, p. 231 236, 2012. p. 234; Torres, Gloria; Shapiro, Anne; Mackey, Tim K. A review of surrogate motherhood regulation in south American countries: pointing to a need for an international legal framework. BMC Pregnancy Childbirth, v. 19, n. 46, p. 1-12, 2019; PIERSANTI, Valeria et al. Surrogacy and "Procreative Tourism": what does the future hold from the ethical and legal perspectives? Medicina, v. 57, n. 1, p. 47-63, 2021. p. 50-53. de qualquer orientação sexual, residentes no país ou estrangeiro. Além do mais, o país adota o modelo de gestação por substituição voluntária, não podendo a mãe de aluguel auferir lucros com a gestação, apenas receber o reembolso de uma quantia limitada de despesas relacionadas à gravidez.

Uma realidade completamente diferente, e que, ainda sim, se encontra agrupada na classificação mais permissiva é a de Israel. Até 2018, apenas casais heterossexuais eram contemplados pela lei de barriga de aluguel existente no país. ${ }^{16}$ Ocorre que uma modificação legislativa em tal ano introduziu mulheres solteiras na possibilidade de acesso à maternidade por substituição, excluindo os homens. ${ }^{17} \mathrm{Com}$ isso, casais formados por homens foram impossibilitados de fazer o uso da técnica no país ${ }^{18}$, gerando diversas manifestações. Salienta-se que a prática é permitida, apenas, para os cidadãos daquele país e deve ocorrer na forma voluntária. ${ }^{19}$

Já na Ucrânia, a forma comercial de gestação por substituição foi permitida a partir do ano 2000, inclusive para cidadãos estrangeiros, desde que sejam heterossexuais e casados. ${ }^{20}$ Nota-se que, na utilização em sua forma comercial, o contrato da barriga de aluguel possui várias prerrogativas, como a impossibilidade de a mãe de aluguel ter contato ou ver a criança após o nascimento, sendo permitidas, apenas, informações como comprimento e peso com que o bebê nasceu ${ }^{21}$. Tal questão está relacionada ao próprio Código de Família

$\overline{16}$ BENSHUSHAN, Abraham; SCHENKER, Joseph G. Legitimizing surrogacy in Israel. Human Reproduction, v. 12, n. 8, p. $1832-$ 1834, 1997.

17 BIRENBAUM-CARMELI, Daphna; MONTEBRUNO, Piero. Incidence of surrogacy in the USA and Israel and implications on women's health: a quantitative comparison. Journal of Assisted Reproduction and Genetics, v. 36, p. 2459-2469, 2019. p. 4. Disponível em: https://mpra.ub.uni-muenchen.de/101454/1/MPRA_paper_101454.pdfAcesso em: 03 mar. 2021.

18 Esse fato fez com que houvesse um deslocamento do local de realização da maternidade por substituição por esse grupo para os Estados Unidos e para o sudeste asiático. Tsfati, Maya et al. Fatherhood as a Spatial-contextual phenomenon: Israeli gay fathers through surrogacy. Men and Masculinities, p.1-21, jan. 2020. p. 3-5.

19 ISRAEL tem protestos por lei de "barriga de aluguel" que exclui homens. Exame, São Paulo, jul. 2018. Disponível em: https:/ / exame. abril.com.br/mundo/israel-tem-protestos-por-lei-de-barriga-dealuguel-que-exclui-homens/ Acesso em: 20 jun. 2019.

20 KIRSHNER, Shany Noy. Selling a Miracle? Surrogacy Through International Borders: Exploration of Ukrainian Surrogacy. Journal of International Business and Law, v. 14, n. 1, p. 77-97, jan. 2015. p. 84-86.

${ }^{21}$ BIOTEXCOM. Home. Disponível em: http://mother-surrogate.info/ Acesso em: 20 jun. 2019. 
Ucraniano, que estabelece que, no caso de gestação por substituição, os pais genéticos serão considerados os genitores do bebê. ${ }^{22}$

No que tange à classificação apresentada, um quadro completamente oposto às realidades até então apresentados é a segunda, relacionada aos países que proíbem a maternidade por substituição expressamente, em qualquer condição. Na Alemanha, o Código Civil considera a parturiente a mãe para todos os efeitos, mesmo no caso de doação de óvulos e maternidade por substituição. ${ }^{23-24}$ Cervi e Camera ${ }^{25}$ entendem que esse posicionamento pode ser interpretado como uma medida de cautela em razão do histórico de violação dos direitos humanos na Segunda Guerra Mundial. Dessa maneira, o país criminaliza a técnica, não deixando abertura e possibilidade para que alemães busquem essa alternativa dentro do país.

Na Espanha, além da restrição há, também, norma expressa no sentido de que a mãe é aquela que dá à luz. ${ }^{26}$ Como resposta ao grande número de espanhóis que buscam a gestação por substituição em outros países, admitiu-se a possibilidade de reconhecimento da paternidade ou maternidade biológica e a adoção pelo outro cônjuge ${ }^{27}$. No entanto, contornar a discussão da

22 Art. 123(3) do citado Código: "Whenever an ovum conceived by the husband with another woman is implanted to bis wife, the child is cnsidered to be affiliated to the spouses". Ainda, interessante o art. 139 o qual impede que se conteste a filiação maternal no caso do art. 123(3). UKRANE. Family Code. 2004. Disponível em: jafbase.fr/docEstEurope/FAMILY_CODE_OF_UKRAINE.pdf Acesso em: 03 mar. 2021.

23 EUROPEAN UNION. A comparative study on the regime of surrogacy in EU Member States. Brussels: European Parliamnet, 2013. Disponível em: https://www.europarl.europa.eu/RegData/etudes/ STUD/2013/474403/IPOL-JURI_ET(2013)474403_EN.pdf Acesso em: 03 mar. 2021.

24 Para o texto legal penal alemão, que pune as técnicas de reprodução assistida em casos de maternidade por substituição com pena privativa de liberdade, assim como a de outros países cuja legislação cível não foi explicitada no texto, como França e Grécia. XAVIER, João Proença. Biomedicina reproductiva e direitos humanos. Revista Ibérica do Direito, v. 1, n. 2, p. 19-28, 2020. p. 22-23

25 CERVI, Taciana Damo; CAMERA, Sinara. Os reflexos da Conferência de Haia sobre direito internacional privado em relação à nacionalidade decorrente da maternidade por substituição transnacional. Revista da Faculdade de Direito UFPR, Curitiba, v. 62, n. 3, p. 81-101, set./dez. 2017.

26 EUROPEAN UNION. A comparative study on the regime of surrogacy in EU Member States. Brussels: European Parliamnet, 2013. Disponível em: https://www.europarl.europa.eu/RegData/etudes/ STUD/2013/474403/IPOL-JURI_ET(2013)474403_EN.pdf Acesso em: 03 mar. 2021.

27 PUEYO, Manuel José M. Maternidad subrogada y prestación de maternidad. Revista del Ministerio de Empleo y Seguridad Social, Madrid, n. 116, p. 21-56, 2015; EMALDI-CIRION, Aitziber. Implicaciones maternidade por substituição com essas alternativas parece não diminuir o número de espanhóis que buscam resolver essa questão contratando barriga de aluguel no exterior. $^{28}$

\subsection{A regulação da técnica no ordenamento brasileiro}

Para apresentar a realidade do terceiro grupo da classificação supra realizada, quanto aos países que permitem a maternidade por substituição de forma bastante restritiva, passa-se a observação dos aspectos envolvendo o Brasil. No país, apesar de o primeiro bebê de proveta ter nascido há mais de três décadas (07 de outubro de 1984), ainda não há uma legislação específica para a prática de reproduções medicamente assistidas, tampouco para a técnica da gestação por substituição. No entanto, alguns pontos existentes no ordenamento jurídico podem ajudar a explicitar a visão que o legislador brasileiro e a sociedade adotam como premissas para o tema.

Há quem sustente ${ }^{29}$ que o acesso à gestação por substituição estaria indiretamente garantido na legislação brasileira com base em leitura conjunta entre o art. 226, $\int 7^{\circ}$, da Constituição Federal, a qual aborda o direito de um indivíduo ter filhos, de maneira responsável, competindo ao Estado propiciar o exercício desse direito, o qual, em função disso, dialogaria com os arts. 196 e 198 da Constituição, que versam sobre o dever do Estado à saúde e à prestação de serviço público por intermédio do Sistema Único de Saúde, e com a Lei Federal n. 9.263/1996, que dispõe sobre o planejamento familiar, cujo conceito abrange o conjunto de ações para a

éticas y jurídicas de la maternidad subrogada: Aproximación a una visión europea. Acta Bioethica, Santiago, v. 23, n. 2, p. 227-235, jul. 2017. p. 228.

28 "The Swiss-based International Social Security Association estimates that every year, surrogate mothers give birth to around 20,000 children worldwide. Agencies and parents estimate that between 800 and 1,000 go on to live with Spanish parents, but there are no official figures. There are numbers, however, for international adoptions undertaken by Spaniards, and these have fallen from 5,541 in 2004 to 799 in 2015. Several reasons explain this drop, says the Spanish Health Ministry, including better child protection in the countries of origin". BLANCO, Silvia. Spain struggles with surrogate pregnancy issue. El País, fev. 2017. Disponível em: https://english.elpais.com/ elpais/2017/02/21/inenglish/1487696447_837759.html Acesso em: 03 mar. 2021.

29 CAVALCANTI, Ana Elizabeth Lapa; SCHWARTZ, Germano. Gestação de substituição na sociedade de informação: situação fática e legal no Direito Brasileiro. Revista da Faculdade de Direito do Sul de Minas, Pouso Alegre, v. 34, n. 1, p. 1-23, jan./jun. 2018. p. 7. 
regulação da fecundidade. Outrossim, em nenhum momento, a barriga de aluguel está expressamente referida, sendo este um esforço argumentativo que, ao cabo, não regula a técnica ou os desdobramentos da maternidade via reprodução assistida.

O Código Civil de 2002, ao seu turno, no inciso II do art. 1597, localizado na parte de Relações de Parentesco, elucida que se presumem concebidos na constância do casamento os filhos havidos por fecundação artificial homóloga, mesmo que falecido o marido ${ }^{30}$. Desse dispositivo, há a presunção, apenas, da paternidade e no âmbito matrimonial. Não há uma preocupação no que diz respeito à configuração da maternidade em casos que envolvem fertilização assistida. Além dessa omissão, a forma como está redigido o artigo leva à conclusão de que o ordenamento brasileiro entende como mãe a parturiente. Observa-se que, ao nascer o bebê, a Declaração de Nascido Vivo (DNV) deve ser preenchida com o nome da mãe que deu à luz, não havendo outra possibilidade no documento. ${ }^{31}$

Todavia, o fato de que as normas acompanham o movimento de remodelação da sociedade ficou evidente com a I Jornada de Direito Civil, de 2002, em que se tratou da filiação no que tange à maternidade em reproduções medicamente assistidas. $\mathrm{O}$ enunciado $129^{32}$ aprovado na Jornada propõe que, nos casos de utilização de técnicas de reprodução assistida, a maternidade será estabelecida em favor daquela que forneceu o material genético, ou que, tendo planejado a gestação, valeu-se da técnica de reprodução assistida heteróloga.

Ao proteger as mulheres que podem gestar, as que produzem seus óvulos regularmente e as estéreis, o enunciado coloca em xeque um dos mais tradicionais princípios do Direito: mater semper certa est. ${ }^{33}$ Tal princípio prevê que a mãe da criança seja estabelecida, de forma conclusiva, no momento do nascimento, pelo seu papel

30 BRASIL. Lei n. 10.406, 10 de janeiro de 2002. Institui o Código Civil. Disponível em: http://www.planalto.gov.br/ccivil_03/ Leis/2002/L10406compilada.htm Acesso em: 30 jun. 2019.

31 BRASIL. Ministério da Saúde. Secretaria de Vigilância em Saúde. Manual de Instruções para o preenchimento da Declaração de Nascido Vivo. Brasília, 2011. Disponível em: http://portalarquivos.saude.gov.br/ images/pdf/2017/junho/08/inst_dn.pdf. Acesso em: 30 jun. 2019. 32 BRASIL. Conselho da Justiça Federal. Jornadas de direito civil I, III, IV e V: enunciados aprovados. 2012. Disponível em: https://www. cjf.jus.br/cjf/corregedoria-da-justica-federal/centro-de-estudosjudiciarios-1/publicacoes-1/jornadas-cej/EnunciadosAprovadosJornadas-1345.pdf Acesso em: 30 jun. 2020.

33 DEL'OLMO, Florisbal de Souza. Barriga de aluguel no exterior e a aquisição da nacionalidade brasileira. Revista Brasileira de Direito Animal, Salvador, v. 11, n. 22, p. 177- 200, 2016. p. 181. no evento. Contudo, o avanço da medicina e a remodelagem familiar não permitem que essa ideia permaneça intacta.

Consoante justificativa do enunciado, foi frisado que, em hipótese alguma, será permitido fim lucrativo por parte da mãe sub-rogada. Esse posicionamento, também, é observado nos Projetos de Lei que a tramitaram e tramitam no Congresso Nacional, conforme observado por Del'Olmo ${ }^{34}$. Entre eles, podemse citar o PL n. 3.638/1993, o PL no 2.855/1997, o PL no 4.655/2001, o PL n ${ }^{\circ} 1.135 / 2003$, o PL n. ${ }^{\circ} 1.184 / 2003$, o PL n. ${ }^{\circ}$ 2.061/2003, o PL n. ${ }^{\circ}$ 4.892/2012 e o PL n. ${ }^{\circ}$ 115/2015. Em sua maioria, eles proíbem a gestação por sub-rogação na sua forma comercial. Tal proibição certamente tem como embasamento a Constituição Federal Brasileira, que, em seu art. 199, $\int 4^{\circ}$, proíbe a comercialização do corpo ou parte dele. ${ }^{35}$

Os documentos que versam, de forma mais direta, a respeito da reprodução medicamente assistida e da gestação por substituição no Brasil são aqueles produzidos pelo Conselho Federal de Medicina (CFM), que estabelecem resoluções para direcionar condutas médicas em todo o território nacional. Apesar de as normas em questão possuírem caráter deontológico, dirigidas à sociedade médica, conhecer as bases em que estas se fundamentam pode auxiliar a compreensão de um futuro posicionamento do legislador ao regular especificamente o tema.

Dentre as cinco Resoluções existentes ${ }^{36}$, a de n. 2.121 de 2015, possui uma dupla importância a ser destacada.

34 DEL'OLMO, Florisbal de Souza. Barriga de aluguel no exterior e a aquisição da nacionalidade brasileira. Revista Brasileira de Direito Animal, Salvador, v. 11, n. 22, p. 177- 200, 2016. p. 181.

35 BRASIL. [Constituição (1988)]. Constituição da República Federativa do Brasil. Disponível em: http://www.planalto.gov.br/ccivil_03/ Constituicao/Constituiçao.htm Acesso em: 30 jun. 2019.

36 CONSELHO FEDERAL DE MEDICINA. Resolução $n^{\circ}$ 1.358/1992. Disponível em: http://www.portalmedico.org.br/ resolucoes/CFM/1992/1358_1992.htm. Acesso em: 30 jun. 2019; CONSELHO FEDERAL DE MEDICINA. Resolução $n^{\circ}$ 1.957/2010. Disponível em: http://www.portalmedico.org. br/resolucoes/CFM/2010/1957_2010.htm Acesso em: 30 jun. 2019; CONSELHO FEDERAL DE MEDICINA. Resolução $n^{\circ}$ 2.013/2013. Disponível em:http://www.portalmedico.org.br/resolucoes/CFM/2013/2013_2013.pdf Acesso em: 30 jun. 2019; CONSELHO FEDERAL DE MEDICINA. Resolução no 2.121/2015. Disponível em: http://www.cremers.org.br/dowload/2121-2015. pdf. Acesso em 30 jun. 2019; CONSELHO FEDERAL DE MEDICINA. Resolução $n^{0}$ 2.168/2017. Disponível em: https://www. legisweb.com.br/legislacao/?id=352362 Acesso em: 03 mar. 2021. Para um debate acerca das resoluções mais antigas, vide: CAVALCANTI, Ana Elizabeth Lapa; SCHWARTZ, Germano. Gestação de substituição na sociedade de informação: situação fática e legal no 
A primeira refere-se ao fato de que, em seu texto, são apresentados princípios e condutas a serem seguidos pelos médicos no manuseio de técnicas de reprodução medicamente assistida. Dentre essas diretrizes, pode-se observar a impossibilidade de usar a técnica para a escolha do sexo ou de qualquer característica biológica do futuro filho; a proibição de caráter lucrativo comercial na doação de gametas e o limite de quatro óvulos fertilizados a serem implementados por mulher. Ademais, o documento de 2015 trouxe também duas novidades em relação às resoluções anteriores: a primeira refere-se à possibilidade de gestação compartilhada em união homoafetiva feminina em que não haja infertilidade, e a segunda discorre sobre a possibilidade excepcional de que mulheres, com mais de 50 anos, possam utilizar essas técnicas. ${ }^{37}$

De forma mais direta, a citada Resolução de 2015 aborda a gestação por substituição ao determinar três requisitos a serem preenchidos. ${ }^{38} \mathrm{O}$ primeiro trata da possibilidade do uso da técnica nos casos em que houver algum problema médico que impeça ou contraindique a gestação na doadora genética ou em caso de união homoafetiva. Observa-se a necessidade de um laudo médico contraindicando a gestação. Além disso, a cedente do útero deve pertencer à família de um dos genitores do projeto parental, tendo parentesco consanguíneo até o quarto grau (isto é, mãe, avó, irmã, tia e prima). Caso não exista esse parentesco, o procedimento somente será possível após aprovação do Conselho Regional de Medicina. Por último, frisa-se a impossibilidade de cessão temporária do útero com caráter comercial ou lucrativo.

Outrossim, essa norma foi revogada em 2017 pela Resolução de n. 2.168 do CFM, mas as regras previstas em tal Resolução não foram totalmente alteradas. ${ }^{39} \mathrm{Em}$

Direito Brasileiro. Revista da Faculdade de Direito do Sul de Minas, Pouso Alegre, v. 34, n. 1, p. 1-23, jan./jun. 2018. p. 14-15.

37 CONSELHO FEDERAL DE MEDICINA. Resolução $n^{\circ}$ 2.121/2015. Disponível em: http://www.cremers.org.br/dowload/2121-2015.pdf. Acesso em 30 jun. 2019. Para um comentário sobre a Resolução de 2015, vide: DEL'OLMO, Florisbal de Souza. Barriga de aluguel no exterior e a aquisição da nacionalidade brasileira. Revista Brasileira de Direito Animal, Salvador, v. 11, n. 22, p. 177- 200, 2016.

38 CONSELHO FEDERAL DE MEDICINA. Resolução $n^{\circ}$ 2.121/2015. Disponível em: http://www.cremers.org.br/dowload/2121-2015.pdf. Acesso em 30 jun. 2019.

39 CONSELHO FEDERAL DE MEDICINA. Resolução $n^{\circ}$ 2.168/2017. Disponível em: https://www.legisweb.com.br/ legislacao/?id=352362 Acesso em: 03 mar. 2021. Para um comen- relação aos preceitos estipulados pela medida de 2015, na verdade, podem-se avultar três pontos comparativos: um ampliativo, um modificativo e um explicativo. Quanto ao primeiro, destaca-se a possibilidade de cessão temporária do útero para familiares em grau de parentesco consanguíneo descendente não limitado mais ao quarto grau, também abrangendo, agora, na Resolução de 2017, filha e sobrinha. Quanto ao segundo, se na Resolução de 2015 os embriões com mais de cinco anos poderiam ser descartados se esta fosse a vontade dos envolvidos, esse prazo hoje restou reduzido para três. Por fim, em relação ao último, restou definida no texto a já permitida gestação compartilhada para casos de união homoafetiva feminina.

Logo, em função da inexistência de legislação federal que regulamente especificamente o uso das técnicas de reprodução humana assistida, como observado supra, o tema acaba sendo orientado pelo CFM, muito embora tais Resoluções não tenham forca de lei ${ }^{40}$. As dificuldades enfrentadas para regular a gestação por substituição no país, assim, contrastam com países que já têm um posicionamento consolidado, mesmo que não haja harmonização em nível internacional. Essas divergências estimulam pessoas interessadas no uso da técnica a buscarem países cuja legislação seja mais permissiva, provocando o chamado "turismo reprodutivo", o qual pode trazer inúmeras consequências para o Direito Internacional Privado.

\section{A atuação do direito internacional privado na gestação por substituição}

As divergências entre os países a respeito da gestação por substituição apontam para questões de caráter ético e jurídico de Direito Internacional Privado. Delimitar a autonomia privada para o uso da técnica, além de ponderar sobre a ordem pública e o melhor interesse

tário sobre a Resolução de 2017: SARLET, Gabrielle Bezerra S.; ANDRADE, Denise Almeida. A parentalidade corresponsável e a maternidade por sub-rogação: uma análise a partir do enfoque jurídico dos sistemas normativos brasileiro e português. Pensar - Revista de Ciências Jurídicas, v. 25, n. 1, p. 1-15, jan./mar. 2020. p. 8.

40 RIVABEM, Fernanda S.; GLITZ, Frederico. Bebê globalizado: a gestação de substituição e o direito internacional privado brasileiro. Revista da Faculdade Mineira de Direito, v. 23, n. 46, p. 249-270, 2020. p. 253. 
da criança, está entre os principais desafios dessa realidade global.

A Conferência de Direito Internacional Privado da Haia $(\mathrm{HCCH})$ pode ter um importante papel para a resolução desses conflitos, caso consiga estabelecer princípios e, no futuro, um tratado internacional sobre a maternidade por substituição. Isso porque, o diálogo internacional é o principal instrumento para que sejam estabelecidos direitos mínimos comuns que permitam o uso dessa técnica sem violar a dignidade da pessoa humana.

\subsection{Os desafios enfrentados frente à variedade de sistemas}

A difusão alcançada pela técnica da gestação por substituição encontra como obstáculo, para seu maior êxito, a variedade de abordagens encontradas no globo. É notável que cada país percebe a maternidade por substituição sob a ótica de sua cultura, além de ser embasada em seus aspectos históricos e políticos. Fato natural, haja vista que, por ser uma técnica recente, a dificuldade de se delimitar suas consequências e riscos é recebida de forma diferente a depender da localidade.

Contudo, apesar da existência de sistemas diversos, dois tipos de problemas são constantemente identificados quando se trata da maternidade sub-rogada. O primeiro deles é a discussão quanto à possível banalização da técnica, caso não seja utilizada de forma adequada, controlada e fiscalizada. Já a segunda questão refere-se ao embate entre a preponderância da ordem pública ou do melhor interesse da criança no que tange à aquisição de nacionalidade em países que não permitem tal meio de reprodução assistida.

Esses dois desafios, que serão melhor apresentados a seguir, apresentam um ponto em comum: ambos perpassam pela ideia base da necessidade de tutela da dignidade da pessoa humana dos envolvidos. Nessa perspectiva, Brauner ${ }^{41}$ ressalta que as novas tecnologias oferecem uma gama de possibilidades à mulher e ao homem para a realização de um projeto de parentalidade. No entanto, cabe uma reflexão sobre quais procedimentos podem ser realizados sem afrontar, diretamente, os

${ }_{41}$ BRAUNER, Maria Cláudia Crespo. Novas tecnologias reprodutivas e projeto parental: contribuição para o debate brasileiro. 2003. Disponível em: https://www.ufrgs.br/bioetica/repbrau.htm Acesso em: 20 jul. 2019. seus direitos fundamentais e, igualmente, os da criança, que deve ter o direito de nascer com a dignidade devida a todos os seres humanos.

Destarte, para evitar a banalização desse progresso científico na área de reprodução, é imprescindível o uso de princípios bioéticos que afirmem a dignidade da pessoa humana, a qual pode ser entendida como a

[...] qualidade intrínseca e distintiva de cada ser humano que o faz merecedor do mesmo respeito e consideração por parte do Estado e da comunidade, implicando, neste sentido, um complexo de direitos e deveres fundamentais que assegurem a pessoa tanto contra todo e qualquer ato de cunho degradante e desumano, como venham lhe garantir as condições existenciais mínimas. ${ }^{42}$

O levantamento dessa discussão ocorre, justamente, pelo número de casos registrados de bebês gerados por maternidade por substituição que foram rejeitados por apresentarem alguma deficiência. Além disso, o anexo II da Conferência de Haia de 2014, em seu documento preliminar $n .^{\circ} 3 \mathrm{~A}^{43}$, apresenta não somente situações dessa natureza, mas também o uso irregular da gestação por substituição para possível tráfico de bebês.

O primeiro caso apontado no relatório sobre casos ocorridos em 2014 é o famoso "Baby Gammy”, que viralizou na mídia pelo chocante abandono de um bebê com Síndrome de Down e algumas deficiências respiratórias pelos pretensos pais australianos. O casal que contratou o serviço de maternidade por substituição na Tailândia deu sua versão dos fatos, relatando que a agência que gerenciava o procedimento foi fechada e que a língua se tornou uma barreira entre o casal e a mãe substituta para compreender o que estava acontecendo. ${ }^{44}$

Aos quatro meses de gestação, a mãe substituta foi informada de que estava grávida de gêmeos, e que um deles possuía Síndrome de Down. O casal alegou desconhecer tal informação e que somente descobriram a presença de gêmeos quando voltaram para buscar o pretenso filho. Por fim, os australianos levaram, apenas, o bebê saudável, deixando aquele com Síndrome de

42 SARLET, Ingo Wolfgang. Dignidade da pessoa humana e direitos fundamentais na Constituição Federal de 1988. Porto Alegre: Livraria do Advogado, 2011. p. 60.

43 HAGUE CONFERENCE ON PRIVATE INTERNATIONAL LAW. Prel. Doc. N.o 3. The parantage/surrogacy Project: na updating note. 2015. Disponível em: https://assets.hcch.net/upload/ wop/gap2015pd03a_en.pdf Acesso em: 01 jul. 2019.

44 SARMENTO, Liv Azevedo. A gestação de substituição e seus desafios no Direito Internacional Privado. 2019. Dissertação (Mestrado em Direito) - Universidade de São Paulo, São Paulo, 2019. p. 53-55. 
Down com a mãe substituta, que não havia se planejado para ficar com nenhum dos bebês gerados. A mãe substituta, por sua vez, afirma que, ao descobrirem a gravidez de gêmeos e a deficiência de um deles, o casal solicitara que ela abortasse. Contudo, considerando-se os preceitos culturais e religiosos seguidos pela mãe, esta optou por continuar a gestação. Ao nascerem os gêmeos, os pretensos pais a encontraram e levaram, apenas, o bebê considerado saudável. ${ }^{45}$

Independentemente de quais alegações sejam reais, além do visível prejuízo ao bebê com Síndrome de Down, fora constatado o risco a que a bebê levada pelos pretensos pais estava exposta: posteriores investigações descobriram que um dos pretensos pais australianos já havia sido condenado por abuso sexual contra crianças no ano de $1997 .{ }^{46}$

Tais situações não ocorrem, apenas, em países como a Tailândia, que não regulamentam o instituto. É notório que a falta de fiscalização, inclusive em países que regulam a prática comercial dessa técnica, também pode gerar situações suspeitas de violar direitos fundamentais dos indivíduos. Um exemplo é a agência BioTexCom ${ }^{47}$ que realiza o serviço completo da gestação por substituição de forma comercial, possuindo como polo a Ucrânia e diversos escritórios pelo mundo.

Nela, mães de substituição são selecionadas, há acompanhamento pré-natal, os pais formuladores do projeto parental podem escolher a quantidade de meses que desejam ficar pelo local para acompanhar os exames. Contudo, apesar do reconhecimento internacional da BioTexCom nesse ramo, a agência já se viu inserida em um escândalo, acusada de delito fiscal, possível falsificação de documentos e tráfico de bebês em $2018 .{ }^{48}$

45 SARMENTO, Liv Azevedo. A gestação de substituição e seus desafios no Direito Internacional Privado. 2019. Dissertação (Mestrado em Direito) - Universidade de São Paulo, São Paulo, 2019. p. 53-55.

46 MÃE de aluguel tinha concordado em ficar com bebê com Down, diz agente. G1, São Paulo, 2014. Disponível em: http:// g1.globo.com/mundo/noticia/2014/08/mae-de-aluguel-concordou-em-ficar-com-bebe-com-down-diz-agente.html Acesso em: 20 jul. 2019.

47 ROVATI, Lola. El escándalo de BioTexCom, la clínica de maternidad subrogada ucraniana investigada por posible falsedad documental, delito fiscal y tráfico de bebés. Bebés y más, set. 2018. Disponível em: https://www.bebesymas.com/noticias/escandalobiotexcom-clinica-maternidad-subrogada-ucraniana-investigadaposible-falsedad-documental-delito-fiscal-trafico-bebes Acesso em: 02 jul. 2019.

48 Ferber, Sarah; Marks, Nicola S.; Mackie, Vera. Oocytes, Surrogacy and Cross-Border Reproduction. In: FERBER, Sarah; Marks,
Essas situações demonstram como a falta de regulamentação, associada à fiscalização e medidas de afirmação éticas, podem provocar sérios danos, não somente aos bebês, mas também aos autores de projetos parentais que vez ou outra são enganados e às mães substitutas. Essas últimas, em sua maioria, são mulheres de menor poder aquisitivo e vulneráveis a situações degradantes, como o uso da gestação sem controle e ausência de direitos mínimos assegurados.

Já o segundo desafio constantemente observado, ocorre no momento do registro da criança no país dos pais autores do projeto parental. A difícil decisão de aquisição de nacionalidade gira em torno do que deve prevalecer: a ordem pública e/ou bons costumes, ou o melhor interesse da criança. ${ }^{49}$ Isso significa que, muitas vezes, países que não regulamentam o uso dessa técnica causam entraves diante de uma situação de registro de bebê por pais que utilizaram da substituição. ${ }^{50}$

Com base nesse argumento, para fins de reflexão, propõe-se o seguinte exemplo: um casal contrata a maternidade por substituição em um país em que a legislação determina que a criança adquirirá nacionalidade de seus pais legais (isto é, os autores do projeto parental). Ao chegarem no país de origem dos pais, as leis locais indicam que o bebê deveria ter a nacionalidade do país em que nasceu, em virtude do ius solis, ou da genitora, em virtude do ius sanguinis, quando inexistente material genético dos "pais legais". ${ }^{1}$

\footnotetext{
"The second scenario can pose difficulties in states where nationality or legal parenthood is tied to biological links, as this means that the child may have no biological link with the intended parent(s), and may instead have a biological link. with a third-party national". ${ }^{2}$
}

Nicola S.; Mackie, Vera. IVF and Assisted Reproduction. Singapura: Palgrave Macmillan, 2020. p. 159-200. p. 172-173.

49 DEL'OLMO, Florisbal de Souza. Barriga de aluguel no exterior e a aquisição da nacionalidade brasileira. Revista Brasileira de Direito Animal, Salvador, v. 11, n. 22, p. 177- 200, 2016. p. 193.

50 CERVI, Taciana Damo; CAMERA, Sinara. Os reflexos da Conferência de Haia sobre direito internacional privado em relação à nacionalidade decorrente da maternidade por substituição transnacional. Revista da Faculdade de Direito UFPR, Curitiba, v. 62, n. 3, p. 81-101, set./dez. 2017. p. 90.

51 Situação exemplificativa adaptada de: GHRAINNE, Brid Ni; MCMAHON, Asling. A Public International Law approach to safeguard nationality for surrogate-born children. Legal Studies, v. 37, n. 2, p. 324-342, 2017. p. 325.

${ }_{52}$ GHRAINNE, Brid Ni; MCMAHON, Asling. A Public International Law approach to safeguard nationality for surrogate-born children. Legal Studies, v. 37, n. 2, p. 324-342, 2017. p. 325. Tradução livre: "O segundo cenário pode representar dificuldades em Estados onde a nacionalidade ou a paternidade legal está ligada a ligações 
Esse é o caso, por exemplo, de Israel que, antes de novembro de 2014, reconhecia as crianças concebidas por substituição na Tailândia enquanto nacionais desse país, além de entender que as genitoras por aluguel é que deteriam o pátrio poder, de modo que elas não podiam sair do país sem a sua autorização - o que somente era revertido quando as Cortes Tailandesas determinavam o poder dos contratantes (pais legais) sob tais bebês, permitindo, assim, a sua ida para Israel, em que pese nada pudesse ser feito em relação à nacionalidade. ${ }^{53}$

Furthermore, given that many rights and responsibilities flow from the state to its nationals and this entails an economic burden for the state, states are often reluctant to recognise international surrogate cbildren as their nationals. As a consequence, international surrogate children can be rendered stateless. ${ }^{54}$

Nessa hipótese, a apatridia é outro problema que pode derivar da maternidade por substituição em virtude da ordem pública doméstica e/ou os bons costumes de certas nações que impedem a transmissão da nacionalidade dos pais legais à criança ao imporem restrições a sua concessão àqueles que não preenchem seus requisitos legais ou por terem sido concebidos/gerados, ilicitamente, segundo os seus ordenamentos. ${ }^{55}$

biológicas, pois isso significa que a criança pode não ter nenhuma ligação biológica com o(s) pai(s) pretendido(s) e, em vez disso, pode ter uma ligação biológica com um terceiro nacional".

53 CAAMANO, Jessica M. International, commercial, gestational surrogacy through the eyes of children born to surrogates in Thailand: a cry for legal attention. Boston University Law Review, v. 96, p. 571-607, 2016. p. 587-588.

54 GHRAINNE, Brid Ni; MCMAHON, Asling. A Public International Law approach to safeguard nationality for surrogate-born children. Legal Studies, v. 37, n. 2, p. 324-342, 2017. p. 325. Tradução livre: "Além disso, dado que muitos direitos e responsabilidades fluem do estado para seus nacionais e isso acarreta um fardo econômico para o estado, os estados muitas vezes relutam em reconhecer as crianças substitutas internacionais como seus nacionais. Como consequência, filhos substitutos internacionais podem se tornar apátridas".

${ }_{55}$ De se ressaltar, segundo Del'Olmo, que o Brasil não faz nenhuma menção quanto a forma em que a criança foi concebida e gerada por ocasião da solicitação do registro consular, de modo que esse não seria o caso brasileiro. "[A] tradição brasileira moderna tem sido de respeito à lei do foro no que tange documentos locais. Nesse sentido, não ocorrendo litígio sobre a relação contratual entre as partes e havendo certidão local de nascimento lavrada nos termos das normas do país, não haveria razão para que a Autoridade Consular brasileira extrapolasse suas funções questionando a validade jurídica de um contrato que não diz respeito diretamente ao ato sob sua responsabilidade: o registro de nascimento válido no local em que foi emitido, com base no qual ela lavrará o registro consular de nascimento brasileiro". DEL'OLMO, Florisbal de Souza. Barriga de aluguel no exterior e a aquisição da nacionalidade brasileira. Revista Brasileira de Direito Animal, Salvador, v. 11, n. 22, p. 177- 200, 2016.
Por outra banda, mesmo que considerada uma situação de anacionalidade, vale ressaltar que esta deveria ser combatida à luz da Convenção para a Redução do Número de Apátridas de $1961^{56}$, a qual impõe aos Estados-Partes a obrigação de concessão de nacionalidade à apátridas ${ }^{57}$, o que contemplaria os casos de maternidade por substituição. Porém, para os Estados não signatários, não haveria a obrigação de concessão de nacionalidade, persistindo o problema da apatridia.

E, justamente a respeito dessa hipótese, deve-se- relembrar o Princípio do Superior Interesse da Criança, cujo pressuposto é justamente o resguardo da dignidade humana, permitindo que esta usufrua dos direitos enquanto nacional do Estado de seus pais legais. Assim, "with an unwavering focus on protecting the child's rights and the new family's physical unity", esse princípio deveria ser o norteador das relações jurídicas derivadas da maternidade por substituição, as quais incluem a atribuição de nacionalidade idêntica à dos pais legais à criança. ${ }^{58-59-60}$

p. 192.

56 ORGANIZAÇÃO DAS NAÇÕES UNIDAS. Convenção para a redução do Número de Apatridia. Nova York, 30 ago. 1961. Disponível em: https://www.acnur.org/fileadmin/Documentos/portugues/ BDL/Convencao_para_a_Reducao_dos_Casos_de_Apatridia_ de_1961.pdf Acesso em: 04 fev. 2021.

57 São 76 Estados-Partes em fevereiro de 2021. A lista completa em: ORGANIZAÇÃO DAS NAÇÕES UNIDAS. United Nations tretaty collection: Convention on the Reduction of Statelessness. Disponível em: https://treaties.un.org/pages/ViewDetails. aspx?src $=$ TREATY\&mtdsg_no $=V-4 \&$ chapter $=5$ Acesso em: 05 fev. 2021.

58 CAAMANO, Jessica M. International, commercial, gestational surrogacy through the eyes of children born to surrogates in Thailand: a cry for legal attention. Boston University Law Review, v. 96, p. 571-607, 2016. p. 588. Tradução nossa: “[...] solicitando a proposição de que essas questões sejam resolvidas da melhor maneira interesses da criança com um foco inabalável na proteção dos direitos da criança e a unidade física da nova família" (destaque para a tradução do trecho que está no texto principal).

59 Para um resgate sobre como alguns países interpretam a atribuição de nacionalidade. EUROPEAN UNION. The citizenship of children born to surrogates. Brussels: European Centre for Parliamentary Research and Documentation, 2018. Disponível em: www. epgencms.europarl.europa.eu/cmsdata/upload/3a09689d-dabe42ad-b996-e01d9778a99f/No_22_The_citizenship_of_children_ born_to_surrogates.pdf Acesso em: 12 mar. 2021.

${ }^{60}$ Apesar de não ser um caso envolvendo nacionalidade, salientase o uso deste princípio como base para o caso da bebê M.L.C no judiciário brasileiro, em que o "Conselho Superior da Magistratura do Estado de São Paulo, órgão responsável pelas decisões de última instância que envolvam registros públicos daquele estado, foi solicitado para determinar a quem caberia a maternidade de uma criança gerada mediante fertilização in vitro". O resultado fora de que, com base no melhor interesse da criança, deveria ser lavrado o assento de nascimento constando como pais os fornecedores de material genético utilizados na fertilização. TEIXEIRA, Caroline Rocha Pereira. 
Esse princípio, hodiernamente, compõe a ordem pública internacional, devendo ser observado no atual contexto de globalização e mobilidade enquanto um limitador da conduta estatal. ${ }^{61}$ Por isso, inclusive, aduz-se sobre a necessidade de os Estados harmonizarem seus entendimentos para que o melhor interesse da criança sempre prevaleça nesses casos.

\subsection{O posicionamento da Conferência de Direito Internacional Privado da Haia}

Percebe-se que os benefícios provenientes da técnica de gestação por substituição, tão caros àqueles que buscam realizar o sonho da maternidade ou paternidade, podem se tornar a causa geradora de violação de direitos. Para que isso não ocorra, o Direito Internacional Privado deve dialogar a respeito do assunto, haja vista que, no atual mundo, onde a mobilidade prospera, legislações sem um mínimo de convergência entre si impedem que essa conquista seja usufruída de forma plena.

Nessa perspectiva, os efeitos internacionais da gestação por substituição estão ganhando destaque juntamente à Conferência de Direito Internacional Privado da Haia $(\mathrm{HCCH})$. Essa organização se dedica à codificação do Direito Internacional Privado por meio da regulamentação de diversas áreas pertinentes aos países participantes. Em maio de 1993, a Resolução adotada na $17^{\mathrm{a}}$ Sessão apontou que a Conferência ${ }^{62}$ estava se tor-

A maternidade de substituição e o conflito de presunção de maternidade certa: estudo de casos. Revista de Doutrina Jurídica, v. 108, n. 1, p. 125-144, 2017. p. 135-136. Ação semelhante também ocorrera no Rio Grande do Sul: trata-se do processo no 017/1.10.0005360-6 que correu junto à Comarca de Lajeado, em que "uma mãe biológica ingressou com ação de autorização judicial para registro de nascimento, alegando ter realizado fertilização in vitro com seu material genético e de seu marido, utilizando útero de substituição temporária". O juiz, no caso, afirmou que declarar o casal autor do projeto parental como pai e mãe biológicos do bebê coincide com o melhor interesse da criança. LANDMEIER, Felipe Redecker; SCHMIDT, Alice Krämer Iorra. A (im)possibilidade jurídica de elaboração de contrato de gestação de substituição. Revista Destaques Acadêmicos, Lajeado-RS, v. 8, n. 2, p. 93-110, 2016. p. 105.

${ }^{61}$ ARAUJO, Nadia de; VARGAS, Daniela Trejos; MARTEL, Letícia de Campos Velho. A gestação de substituição: regramento no direito brasileiro e seus aspectos de direito internacional privado. In: BAPTISTA, Luiz Olavo; RAMINA, Larissa; FRIEDRICH, Tatyana Scheila (coord.). Direito Internacional Contemporâneo. Curitiba: Juruá, 2014. p. 502. Disponível em: http://nadiadearaujo.com/ wpcontent/uploads/2015/03/GESTA $\%$ C3\%87\%C3\%83o-de substitui $\%$ c3\%87\%c3\%83o-regramento-no-direito-brasileiro-eseus-aspectos-de-direitointernacional-privado.pdf. Acesso em: 20 jun. 2019.

62 HAGUE CONFERENCE ON PRIVATE INTERNATION- nando um polo mundial a serviço da cooperação judicial e administrativa internacional no domínio do direito privado e, em particular, na área da proteção infantil.

A maternidade por substituição foi abordada pela primeira vez em junho de 2010, oportunidade em que a Comissão Especial avaliou a utilização da Convenção sobre adoção internacional para tratar o tema e verificou que não seria adequado. Sendo assim, era necessária uma discussão e regulamentação específica para a gestação por substituição, recomendando-se ao Secretariado averiguar melhor o assunto e repercussão no Direito Internacional. É o que pode ser observado conforme o documento produzido pelas reuniões:

\section{[...] La Comisión Especial observa que el número de acuerdos de maternidad subrogada en el ámbito internacional está aumentando rápidamente. Esta Comisión expresa su preocupación sobre la incertidumbre que supone respecto a la situación jurídica de muchos niños que han nacido como resultado de estos acuerdos y considera inadecuado el uso del Convenio en los casos de maternidad subrogada en el ámbito internacional. [...] La Comisión Especial recomienda que la Conferencia de La Haya desarrolle estudios sobre los temas legales, especialmente en materia de Derecho Internacional Privado, relacionados con la maternidad subrogada. ${ }^{63}$}

Seguindo as diretrizes, o Secretariado produziu um documento específico, denominado Documento Preliminar n. 11 (março de 2011), e apresentou-o em abril de $2011 .{ }^{64} \mathrm{O}$ documento expressou que as preocupações mais amplas até então sobre o tema seriam: a proteção das pessoas vulneráveis envolvidas (as crianças, as mães substitutas e os pretensos pais); a regulamentação das agências; a cooperação entre as autoridades dos Esta-

AL LAW. Resolution adopted by the $17^{a}$ Session of the Hague Conference on private international law. 1933. Disponível em: https://www.hcch.net/ pt/about/more-about-hcch/resolution Acesso em: 02 jul. 2019.

63 HAGUE CONFERENCE ON PRIVATE INTERNATIONAL LAW. Comisión Especial sobre el funcionamiento práctico del Convenio de La Haya de 29 de mayo de 1993 relativo a la protección del niño y a la cooperación en materia de adopción internacional. Haia, jun. 2010. Disponível em: https://assets.hcch.net/upload/wop/adop2010concl_s.pdf. Acesso em: 02 jul. 2019. Tradução livre: “[...] A Comissão Especial observa que o número de acordos de maternidade Barriga de aluguel na arena internacional está aumentando rapidamente. Essa comissão manifesta a sua preocupação com a incerteza que coloca em relação à situação status legal de muitas crianças nascidas como resultado desses acordos e considera inadequado o uso da Convenção em casos de barriga de aluguel no âmbito internacional [...] A Comissão Especial recomenda que a Conferência de Haia desenvolve estudos sobre questões jurídicas, especialmente em questões de Direito Internacional Privado, relacionado à barriga de aluguel".

64 HAGUE CONFERENCE ON PRIVATE INTERNATIONAL LAW. Archive 2000-2018. Disponível em: https://www.hcch. net/pt/governance/council-on-general-affairs/archive Acesso em: 02 jul. 2019. 
dos; e os problemas contratuais. Como conclusão, fora enfatizado que o Secretariado deveria envidar esforços para mapear as possibilidades sobre um consenso entre os países a respeito da temática, além da imprescindível consulta a profissionais de outras áreas (como profissionais da saúde) para o levantamento de problemas.

É nesse momento que surge o importante papel da Associação Americana de Direito Internacional Privado (ASADIP) na temática da maternidade por substituição. Composta por professores e profissionais da área do Direito, a organização tem priorizado a discussão prévia dos temas objeto da Conferência da Haia, contribuindo para negociações com os países. Como resultado, tem-se, em 2012, a apresentação de um novo relatório preliminar de $\mathrm{n}^{\circ}{ }^{0} 10^{65}$, produzido em março, que identificou a necessidade da formação de uma regulamentação de caráter multilateral.

Já no ano de 2013, foi elaborado pelo Secretariado um questionário relativo ao tema, intitulado Documento preliminar $n .^{\circ} 03^{66}$, que foi enviado tanto para os Estados quanto para os profissionais da saúde e do Direito, resultando no Documento Preliminar $n^{\circ} 3 \mathrm{~B}$ de $2014^{67}$. Esse último apontou que, na época, apenas um pequeno número de Estados informou estar envolvido na cooperação transfronteiriça com outros Estados em casos de gestação por substituição.

Além disso, os próximos passos a serem tomados pelos estudos foram sugeridos. Como primeiro ponto, fora incitada a continuação de estudos sobre o tema, ainda não concluído, considerando-se a necessidade de assegurar segurança jurídica e segurança do estatuto legal das crianças e famílias em situações internacionais, e proteger os direitos e o bem-estar de crianças, pais e outras partes envolvidas na concepção de crianças em

65 HAGUE CONFERENCE ON PRIVATE INTERNATIONAL LAW. Archive 2000-2018. Disponível em: https://www.hcch. net/pt/governance/council-on-general-affairs/archive Acesso em: 02 jul. 2019.

66 HAGUE CONFERENCE ON PRIVATE INTERNATIONAL LAW. Prel. Doc $\mathrm{N}^{\circ}$ 3. Questionnaire on the private international law issues surrounding the status of the children, including issues arising from international surrogacy arrangements. 2013. Disponível em: https://assets.hcch.net/upload/wop/gap2014pd3br.pdf Acesso em: 02 jul. 2019.

${ }^{67}$ HAGUE CONFERENCE ON PRIVATE INTERNATIONAL LAW. Prel. Doc. $N^{o} 3 B$. The desirability and feasibility of further work on parentage/surrogacy project. 2014. Disponível em: https://www.hcch.net/pt/governance/council-on-general-affairs/ archive Acesso em: 02 jul. 2019. situações internacionais, de acordo com os padrões globais de direitos humanos estabelecidos.

A segunda diretriz foi a formação de um grupo de experts para facilitar uma maior exploração da viabilidade de um instrumento multilateral vinculativo (ou possíveis medidas não vinculativas). Tal grupo foi criado e convocado a iniciar os trabalhos, tendo como resultados diversas reuniões, de 2016 e até fevereiro de 2019. Atualmente, as discussões giram em torno da tentativa de formulação de um instrumento geral de Direito Internacional Privado sobre o reconhecimento de decisões judiciais sobre a origem legal da criança e seu parentesco.

\subsection{Necessidades patentes e suas influências no Brasil}

As discussões apresentadas no âmbito da Conferência da Haia apontam, em suma, para duas necessidades patentes: a primeira refere-se à urgência de certeza jurídica e segurança na comprovação do status legal das crianças com relação à determinação de seu parentesco em situações de caráter internacional, e a segunda concerne à proteção dos direitos de todos os envolvidos na técnica de reprodução nas situações internacionais.

Acordou-se, como passo inicial, criação de regras em caráter de soft law e de princípios norteadores. Ainda que não haja uma regulamentação fixada sobre o tema, é perceptível que as discussões no âmbito da $\mathrm{HCCH}$ e a busca de uma consolidação de regras já produzem reflexos na forma como alguns países têm julgado questões atinentes à maternidade por substituição.

Cervi e Camera ${ }^{68}$ apresentam um caso ocorrido na Alemanha, relatado nas discussões realizadas na $\mathrm{HCCH}$. Neste, o Tribunal de Justiça Federal do país reformou a decisão de uma corte inferior, conferindo a nacionalidade alemã para uma criança nascida por maternidade por substituição no estado da Califórnia, nos Estados Unidos. Fora rejeitada, de forma mais específica, a hipótese de adoção acolhida pelo tribunal inferior, pois uma adoção, na presente situação, implicaria o risco de que os pais mudassem de ideia e não mais a desejassem

68 CERVI, Taciana Damo; CAMERA, Sinara. Os reflexos da Conferência de Haia sobre direito internacional privado em relação à nacionalidade decorrente da maternidade por substituição transnacional. Revista da Faculdade de Direito UFPR, Curitiba, v. 62, n. 3, p. 81-101, set./dez. 2017. p. 96. 
após o nascimento da criança. Assim, fora invocado o Princípio do Melhor Interesse da Criança e a ideia de que esta não deveria ser penalizada pelas ações dos pais.

Outro posicionamento modificado após as discussões na HCCH diz respeito a uma decisão do Conselho de Estado na França. O Conselho confirmou a validade de uma circular emitida em 25 de janeiro de 2013 pelo Ministro da Justiça no que tange à emissão de certificados de cidadania francesa para filhos nascidos no estrangeiro em decorrência de maternidade por substituição. O entendimento balizador é fato de que ainda que a legislação francesa considere nulo o contrato de maternidade por substituição, não pode privar a criança da nacionalidade francesa. ${ }^{69}$

Consequentemente, a Conferência da Haia também pode influenciar a forma como o Brasil trata a matéria. Em especial, a notar que a falta de regulamentação evidencia a necessidade de diálogo tanto no âmbito local quanto internacional para consolidar perspectiva brasileira sobre o assunto e regulamentar direitos básicos para os envolvidos.

Araújo, Vargas e Martel $^{70}$ apontam os principais pontos que uma futura regulamentação brasileira deveria abordar, sendo a opção da legislação por um contrato do tipo oneroso ou gratuito a primeira necessidade apontada. A falta de regulamentação faz com que, atualmente, as partes firmem contrato de gestação por substituição de maneira informal ${ }^{71}$, não apresentando

69 CERVI, Taciana Damo; CAMERA, Sinara. Os reflexos da Conferência de Haia sobre direito internacional privado em relação à nacionalidade decorrente da maternidade por substituição transnacional. Revista da Faculdade de Direito UFPR, Curitiba, v. 62, n. 3, p. 81-101, set./dez. 2017. p. 96-97.

70 ARAUJO, Nadia de; VARGAS, Daniela Trejos; MARTEL, Letícia de Campos Velho. A gestação de substituição: regramento no direito brasileiro e seus aspectos de direito internacional privado. In: BAPTISTA, Luiz Olavo; RAMINA, Larissa; FRIEDRICH, Tatyana Scheila (coord.). Direito Internacional Contemporâneo. Curitiba: Juruá, 2014. p. 494. Disponível em: http://nadiadearaujo.com/ wpcontent/uploads/2015/03/GESTA $\%$ C3\%87\%C3\%83o-de substitui $\%$ c3\%87\%c3\%83o-regramento-no-direito-brasileiro-eseus-aspectos-de-direitointernacional-privado.pdf. Acesso em: 20 jun. 2019.

${ }^{71}$ Ressalte-se que a Resolução no 2.013/2013 do CFM considera "necessária a elaboração de um contrato a fim de definir a filiação da criança", muito embora ela "não é suficiente para determinara filiação, já que não há legislação que possibilidade (sic) ao médico responsável pelo parto utilizar-se, desde já, do contrato para efetuar a declaração de nascido vivo em nome dos pais biológicos". LANDMEIER, Felipe Redecker; SCHMIDT, Alice Krämer Iorra. A (im) possibilidade jurídica de elaboração de contrato de gestação de substituição. Revista Destaques Acadêmicos, Lajeado-RS, v. 8, n. 2, p. 93- garantia para o cumprimento da entrega da criança, tampouco a possibilidade de meios legais que imponham a execução do acordo.

Embora a primeira Resolução do CFM editada sobre o tema (n. 1.358/1992 $2^{72}$ já tivesse conceituado a gestação por substituição como doação temporária de útero, referiu-se a normativa, na verdade, à cessão ou empréstimo. Contudo, Lourenzon ${ }^{73}$ observa que o conceito jurídico de comodato ("contrato unilateral gratuito por meio do qual o comodante entrega bem não fungível ao comodatário, o qual deve devolvê-lo após certo tempo" "74) implica a tradição da coisa, o que não ocorre na gestação por substituição, mormente considerando que a gestante não entrega o útero ao casal solicitante. À vista dessa dificuldade de compreensão, a regulamentação pode auxiliar na classificação do uso da técnica no país.

Outro ponto a ser discutido é a possibilidade da determinação da maternidade por força de contrato. Daí surgem duas situações: a primeira se refere ao registro de nascimento, que deve espelhar essa nova situação. Isso porque a declaração de "nascido vivo" é a primeira informação legal sobre a criança, e servirá para que se faça o posterior assentamento de seu nascimento no Registro Civil. Com base nisso, nota-se que, no Manual de Preenchimento (emitido pelo Ministério da Saúde) da referida declaração, há a indicação do cuidado que o profissional deve ter com uma série de informações sobre a parturiente, ali considerada, para todos os efeitos, como sendo a única mãe. ${ }^{75}$

110, 2016. p. 106.

CONSELHO FEDERAL DE MEDICINA. Resolução $n^{\circ}$ 1.358/1992. Disponível em: http://www.portalmedico.org.br/resolucoes/CFM/1992/1358_1992.htm. Acesso em: 30 jun. 2019.

73 LOURENZON, Patrícia Miranda. Contrato de Gestação por substituição: proibi-lo ou torná-lo obrigatório? Doutrinas Essenciais Obrigações e Contratos, São Paulo, v. 4, p.1129-1156, jun. 2011.

74 BRASIL. Lei n. 10.406, 10 de janeiro de 2002. Institui o Código Civil. Disponível em: http://www.planalto.gov.br/ccivil_03/ Leis/2002/L10406compilada.htm Acesso em: 30 jun. 2019.

75 ARAUJO, Nadia de; VARGAS, Daniela Trejos; MARTEL, Letícia de Campos Velho. A gestação de substituição: regramento no direito brasileiro e seus aspectos de direito internacional privado. In: BAPTISTA, Luiz Olavo; RAMINA, Larissa; FRIEDRICH, Tatyana Scheila (coord.). Direito Internacional Contemporâneo. Curitiba: Juruá, 2014. p. 505. Disponível em: http://nadiadearaujo.com/ wpcontent/uploads/2015/03/GESTA $\%$ C3\%87\%C3\%83o-de substitui $\%$ c3\%87\%c3\%83o-regramento-no-direito-brasileiro-eseus-aspectos-de-direitointernacional-privado.pdf. Acesso em: 20 jun. 2019. 
Assim, devem-se anotar as características da gestação e do parto que deram origem ao recém-nascido. No entanto, o único espaço para indicar a mãe é onde se identifica a parturiente. Poderia haver um espaço para casos de gestação por substituição para inserir os pais realizadores do projeto parental. Nesse aspecto, portanto, o avanço de debates na HCCH em torno da construção de um documento que "traga segurança jurídica às crianças no que diz respeito aos seus laços de parentesco" seria de grande valia até mesmo para o Brasil reformar as suas práticas. ${ }^{76}$

Aliás, outro ponto a ser destacado em uma futura regulamentação é a necessidade de um sistema de supervisão e fiscalização das clínicas que se utilizam da técnica em questão. ${ }^{77}$ Tal controle não diz respeito apenas ao aspecto da prática médica, mas também à observância da bioética. Afinal, mesmo que a reprodução assistida perfectibilize o sonho da maternidade/paternidade, somente com a fiscalização e o controle da autonomia privada no uso desta tecnologia é que se pode assegurar um processo que afirme a dignidade da pessoa humana de todos os envolvidos.

Ademais, faz-se importante também determinar, com clareza, os limites impostos àquela que se dispõe a participar como gestante de substituição. A regulação da técnica da gestação por substituição também é uma forma de proteger a mulher que "empresta" o útero. $\mathrm{O}$ não estabelecimento de direitos básicos e limites pode fazer com que esta possa vir a abrir mão de direitos fundamentais (em que pese isto seja juridicamente impossível) em favor de exigências tanto das agências quanto dos pretensos pais.

Por fim, outra implicação da determinação da maternidade são as consequências advindas para a determinação da nacionalidade brasileira. Deve-se lembrar que no Brasil o sistema para aquisição de nacionalidade é

76 CERVI, Taciana Damo; CAMERA, Sinara. Os reflexos da Conferência de Haia sobre direito internacional privado em relação à anacionalidade decorrente da maternidade por substituição transnacional. Revista da Faculdade de Direito UFPR, Curitiba, PR, v. 62, n. 3, pp. 81-101, set./dez. CERVI, Taciana Damo; CAMERA, Sinara. Os reflexos da Conferência de Haia sobre direito internacional privado em relação à nacionalidade decorrente da maternidade por substituição transnacional. Revista da Faculdade de Direito UFPR, Curitiba, v. 62, n. 3, p. 81-101, set./dez. 2017. p. 98.

77 CERVI, Taciana Damo; CAMERA, Sinara. Os reflexos da Conferência de Haia sobre direito internacional privado em relação à nacionalidade decorrente da maternidade por substituição transnacional. Revista da Faculdade de Direito UFPR, Curitiba, v. 62, n. 3, p. 81-101, set./dez. 2017. p. 98. misto, isto é, atribui-se nacionalidade por meio do solo (ius solis) e do sangue (ius sanguinis). ${ }^{78}$ Desse modo, a maternidade por força de contrato estabeleceria um novo critério para a sua declaração, uma vez que a maternidade por substituição poderia assentar um novo tipo de nacionalidade, agora proveniente do contrato, à luz do melhor interesse da criança.

Nesse ponto, interessante verificar a similitude dessas discussões com aquelas envolvendo a concessão de nacionalidade brasileira em casos de adoção internacional $^{79}$, em que se defende tanto a impossibilidade de perda de nacionalidade brasileira para o adotando em virtude da possibilidade de esta poder restar apátrida, o que seria inadmissível no ordenamento jurídico brasileiro em função de suas obrigações internacionais, particularmente, a Convenção para a Redução do Número de Apátridas de 1961, ratificada em $2015^{80}$, e a Convenção sobre o Direito das Crianças de 1989, ratificada em $1990^{81}$; quanto à necessidade de observar o Princípio do Melhor Interesse da Criança, atribuindo-se nacionalidade brasileira à criança nascida no exterior por meio de sentença exarada em processo de adoção internacional, em função do seu "caráter público (ainda que se trate de instituto próprio de direito privado), tendo como objetivo tutelar os direitos fundamentais dos menores (sic)" ${ }^{82}$

78 BRASIL. [Constituição (1988)]. Constituição da República Federativa do Brasil. Disponível em: http://www.planalto.gov.br/ccivil_03/ Constituicao/Constituiçao.htm Acesso em: 30 jun. 2019.

79 Há quem sustente que antes de aprofundarem-se os debates na $\mathrm{HCCH}$, dever-se-ia buscar que os países ratificassem os instrumentos internacionais que tangenciem os problemas em torno da maternidade por substituição já existentes, como as convenções atinentes à apatridia. Veja-se: "[...] we argue that the ratification and im-plementation in domestic law of existing Public International Law conventions provid-ing protection for stateless children should be given priority, as this approach offers the most meaningful solution for such children in the short term". GHRAINNE, Brid Ni; MCMAHON, Asling. A Public International Law approach to safeguard nationality for surrogate-born children. Legal Studies, v. 37, n. 2, p. 324-342, 2017. p. 327.

80 Esta convenção, como aludido anteriormente, impõe a obrigação de conceder-se nacionalidade brasileira aos apátridas de fato ou de direito domiciliados no Brasil. BRASIL. Decreto n. 8.501, 18 de agosto de 2015. Promulga a Convenção para a Redução dos Casos de Apatridia, firmada em Nova Iorque, em 30 de agosto de 1961. Disponível em: www.planalto.gov.br/ccivil_03/_ato2015-2018/2015/ decreto/d8501.htm Acesso em: 30 jun. 2019.

81 Esta convenção impõe, em seu art. $3^{\circ}$, o dever das instituições públicas ou privadas dos Estados-partes em considerar primordialmente o interesse maior da criança. BRASIL. Decreto n. 99.710, 21 de novembro de 1990. Promulga a Convenção sobre os Direitos da Criança. Disponível em: www.planalto.gov.br/ccivil_03/decreto/1990-1994/d99710.htm. Acesso em: 30 jun. 2019.

82 CARDOSO, Tatiana de A. F. R.; FLORES, Mariane C. S.; SILVEIRA, Camila B. A questão da nacionalidade na adoção internac- 
Com isso, nota-se não somente quão relevante são as discussões sobre a construção de um regramento acerca da maternidade por substituição no âmbito da $\mathrm{HCCH}$, como também os diversos impactos que tais debates podem vir a surtir no Brasil, seja no plano do aprimoramento legislativo imposto por uma eventual adesão do país a um documento lá edificado, seja no plano da implementação doméstica dos pressupostos principiológicos lá avultados como essenciais para a apreciação de casos concretos.

\section{Considerações finais}

É cada vez mais urgente discutir as técnicas de reprodução medicamente assistidas no âmbito do Direito, haja vista que o evento que tradicionalmente definia legalmente a maternidade (o parto) não mais se amolda totalmente à realidade. A biotecnologia, por meio do fenômeno chamado split motherbood (maternidade cindida), permitiu identificar a gestante como mãe biológica, a doadora do material como mãe genética e, ainda, a autora do projeto de maternidade como mãe afetiva.

O fato de a maternidade não ser mais una é claramente observável na gestação por substituição, caracterizada quando uma mulher que não pretende assumir a maternidade cede seu corpo para gestar uma criança para outrem. As realidades apontadas no âmbito global evidenciam uma diversidade de tratamentos sobre a temática. Enquanto há países que permitem o uso, inclusive de forma comercial, há aqueles que proíbem, de forma expressa, e, ainda, os que, ao menos, regulamentaram o tema.

A falta de um tratado internacional sobre a maternidade por substituição não é favorável a nenhum dos envolvidos no procedimento. Tanto para aquele que deseja contratar quanto para o que deseja ser contratado, a ausência de normativa que atribua algum tipo de responsabilidade ou condições pode acabar violando direitos fundamentais que não deveriam ser mitigados.

Nesse sentido, as discussões no âmbito da Conferência da Haia, no contexto atual, têm demonstrado avanços sobre o assunto. A deliberação para a formação de um grupo de experts em 2015 e as posteriores reu-

ional. In: ROSA, Conrado Paulino da (org.). Família e sucessões: novos temas e discussões. Porto Alegre: RJR, 2015. p. 22-48. p. 44. niões ocorridas após sua formação apontam para uma tentativa de formulação de um instrumento geral de Direito Internacional Privado sobre o reconhecimento de decisões judiciais a respeito da origem legal da criança e seu parentesco.

Além disso, ficou evidente a influência dessas discussões na tomada de decisão em favor do melhor interesse da criança. Dessa forma, ainda que não exista nenhum documento consolidado e haja, apenas, a busca por regras em caráter de soft law e princípios, a Conferência da Haia de Direito Internacional Privado também pode influenciar a forma como o Brasil trata a matéria. Principalmente a notar que a falta de regulamentação evidencia a necessidade de diálogo, tanto no âmbito local quanto internacional, para consolidar perspectiva brasileira sobre o assunto e regulamentar direitos básicos para os envolvidos.

\section{Referências}

ARAUJO,Nadiade;VARGAS,Daniela'Trejos;MARTEL, Letícia de Campos Velho. A gestação de substituição: regramento no direito brasileiro e seus aspectos de direito internacional privado. In: BAPTISTA, Luiz Olavo; RAMINA, Larissa; FRIEDRICH, Tatyana Scheila (coord.). Direito Internacional Contemporâneo. Curitiba: Juruá, 2014. Disponível em: http://nadiadearaujo.com/wpcontent/ uploads/2015/03/GESTA $\%$ C3\%87\%C3\%83o-de substitui $\%$ c3\%87\%c3\%83o-regramento-no-direitobrasileiro-e-seus-aspectos-de-direitointernacional-privado.pdf. Acesso em: 20 jun. 2019.

ARMOUR, Kim L. Surrogacy Around the World: trends, questions and ethical issues. Nursing for Women's Health, v. 16, n. 3, p. 231-236, 2012.

BENSHUSHAN, Abraham; SCHENKER, Joseph G. Legitimizing surrogacy in Israel. Human Reproduction, v. 12, n. 8, p. 1832-1834, 1997.

BIOTEXCOM. Home. Disponível em: http://mothersurrogate.info/ Acesso em: 20 jun. 2019.

BIRENBAUM-CARMELI, Daphna; MONTEBRUNO, Piero. Incidence of surrogacy in the USA and Israel and implications on women's health: a quantitative comparison. Journal of Assisted Reproduction and Genetics, v. 36, p. 2459-2469, 2019. Disponível em: https:// 
mpra.ub.uni-muenchen.de/101454/1/MPRA_paper_101454.pdf Acesso em: 03 mar. 2021.

BLANCO, Silvia. Spain struggles with surrogate pregnancy issue. El Pais, fev. 2017. Disponível em: https://english.elpais.com/elpais/2017/02/21/inenglish/1487696447_837759.html Acesso em: 03 mar. 2021.

BRASIL. [Constituição (1988)]. Constituição da República Federativa do Brasil. Disponível em: http://www.planalto.gov.br/ccivil_03/Constituicao/Constituiçao.htm Acesso em: 30 jun. 2019.

BRASIL. Conselho da Justiça Federal. Jornadas de direito civil I, III, IV e V: enunciados aprovados. 2012. Disponível em: https://www.cjf.jus.br/cjf/corregedoriada-justica-federal/centro-de-estudos-judiciarios-1/ publicacoes-1/jornadas-cej/EnunciadosAprovadosJornadas-1345.pdf Acesso em: 30 jun. 2019.

BRASIL. Decreto n. 8.501, 18 de agosto de 2015. Promulga a Convenção para a Redução dos Casos de Apatridia, firmada em Nova Iorque, em 30 de agosto de 1961. Disponível em: www.planalto.gov.br/ccivil_03/_ato20152018/2015/decreto/d8501.htm Acesso em: 30 jun. 2019.

BRASIL. Decreto n. 99.710, 21 de novembro de 1990. Promulga a Convenção sobre os Direitos da Criança. Disponível em: www.planalto.gov.br/ccivil_03/decreto/1990-1994/d99710.htm. Acesso em: 30 jun. 2019.

BRASIL. Lei n. 10.406, 10 de janeiro de 2002. Institui o Código Civil. Disponível em: http:/ /www.planalto.gov. br/ccivil_03/Leis/2002/L10406compilada.htm Acesso em: 30 jun. 2019.

BRASIL. Ministério da Saúde. Secretaria de Vigilância em Saúde. Manual de Instruções para o preenchimento da Declaração de Nascido Vivo. Brasília, 2011. Disponível em: http://portalarquivos.saude.gov.br/images/pdf/2017/ junho/08/inst_dn.pdf. Acesso em: 30 jun. 2019.

BRAUNER, Maria Cláudia Crespo. Novas tecnologias reprodutivas e projeto parental: contribuição para o debate brasileiro. 2003. Disponível em: https://www.ufrgs.br/ bioetica/repbrau.htm Acesso em: 20 jul. 2019.

CAAMANO, Jessica M. International, commercial, gestational surrogacy through the eyes of children born to surrogates in Thailand: a cry for legal attention. Boston University Law Review, v. 96, p. 571-607, 2016.
CARDOSO, Tatiana de A. F. R.; FLORES, Mariane C. S.; SILVEIRA, Camila B. A questão da nacionalidade na adoção internacional. In: ROSA, Conrado Paulino da (org.). Família e sucessões: novos temas e discussões. Porto Alegre: RJR, 2015. p. 22-48.

CAVALCANTI, Ana Elizabeth Lapa; SCHWARTZ, Germano. Gestação de substituição na sociedade de informação: situação fática e legal no Direito Brasileiro. Revista da Faculdade de Direito do Sul de Minas, Pouso Alegre, v. 34, n. 1, p. 1-23, jan./jun. 2018.

CERVI, Taciana Damo; CAMERA, Sinara. Os reflexos da Conferência de Haia sobre direito internacional privado em relação à nacionalidade decorrente da maternidade por substituição transnacional. Revista da Faculdade de Direito UFPR, Curitiba, v. 62, n. 3, p. 81-101, set./ dez. 2017.

CONSELHO FEDERAL DE MEDICINA. Resolução $n^{0}$ 1.957/2010. Disponível em: http://www.portalmedico.org.br/resolucoes/CFM/2010/1957_2010.htm Acesso em: 30 jun. 2019.

CONSELHO FEDERAL DE MEDICINA. Resolução $n^{\circ}$ 2.121/2015. Disponível em: http:/ /www.cremers.org. br/dowload/2121-2015.pdf. Acesso em 30 jun. 2019.

CONSELHO FEDERAL DE MEDICINA. Resolução $n^{0}$ 2.168/2017. Disponível em: https://www.legisweb. com.br/legislacao/?id=352362 Acesso em: 03 mar. 2021.

CONSELHO FEDERAL DE MEDICINA. Resolução $n^{0}$ 1.358/1992. Disponível em: http://www.portalmedico.org.br/resolucoes/CFM/1992/1358_1992.htm. Acesso em: 30 jun. 2019.

CONSELHO FEDERAL DE MEDICINA. Resolução $n^{0}$ 2.013/2013. Disponível em:http://www.portalmedico.org.br/resolucoes/CFM/2013/2013_2013.pdf Acesso em: 30 jun. 2019.

DEL'OLMO, Florisbal de Souza. Barriga de aluguel no exterior e a aquisição da nacionalidade brasileira. Revista Brasileira de Direito Animal, Salvador, v. 11, n. 22, p. 177200, 2016.

EMALDI-CIRION, Aitziber. Implicaciones éticas y jurídicas de la maternidad subrogada: Aproximación a una visión europea. Acta Bioethica, Santiago, v. 23, n. 2, p. 227-235, jul. 2017. 
ENGEL, Martin. Cross-border surrogacy: time for a convention? In: BOELE-WOELKI, Katharina et al. Family law and culture in Europe: developments, challenges and opportunities. Cambridge: CUP, 2014. p. 199-216.

EUROPEAN UNION. A comparative study on the regime of surrogacy in EU Member States. Brussels: European Parliamnet, 2013. Disponível em: https://www.europarl. europa.eu/RegData/etudes/STUD/2013/474403/ IPOL-JURI_ET(2013)474403_EN.pdf Acesso em: 03 mar. 2021.

EUROPEAN UNION. The citizenship of children born to surrogates. Brussels: European Centre for Parliamentary Research and Documentation, 2018. Disponível em: www.epgencms.europarl.europa.eu/cmsdata/ upload/3a09689d-dabe-42ad-b996-e01d9778a99f/ No_22_The_citizenship_of_children_born_to_surrogates.pdf Acesso em: 12 mar. 2021.

Ferber, Sarah; Marks, Nicola S.; Mackie, Vera. Oocytes, Surrogacy and Cross-Border Reproduction. In: FERBER, Sarah; Marks, Nicola S.; Mackie, Vera. IVF and Assisted Reproduction. Singapura: Palgrave Macmillan, 2020. p. 159-200.

GHRAINNE, Brid Ni; MCMAHON, Asling. A Public International Law approach to safeguard nationality for surrogate-born children. Legal Studies, v. 37, n. 2, p. 324342, 2017.

HAGUE CONFERENCE ON PRIVATE INTERNATIONAL LAW. Archive 2000-2018. Disponível em: https://www.hcch.net/pt/governance/council-on-general-affairs/archive Acesso em: 02 jul. 2019.

HAGUE CONFERENCE ON PRIVATE INTERNATIONAL LAW. Prel. Doc $N^{\circ} 3$. Questionnaire on the private international law issues surrounding the status of the children, including issues arising from international surrogacy arrangements. 2013. Disponível em: https://assets.hcch.net/upload/wop/gap2014pd3br. pdf Acesso em: 02 jul. 2019.

HAGUE CONFERENCE ON PRIVATE INTERNATIONAL LAW. Prel. Doc. N.o 3. The parantage/surrogacy Project: na updating note. 2015. Disponível em: https://assets.hcch.net/upload/wop/gap2015pd03a_ en.pdf Acesso em: 01 jul. 2019.
HAGUE CONFERENCE ON PRIVATE INTERNATIONAL LAW. Prel. Doc. $N^{0} 3 B$. The desirability and feasibility of further work on parentage/surrogacy project. 2014. Disponível em: https://www.hcch. net/pt/governance/council-on-general-affairs/archive Acesso em: 02 jul. 2019.

HAGUE CONFERENCE ON PRIVATE INTERNATIONAL LAW. Resolution adopted by the $17^{a}$ Session of the Hague Conference on private international law. 1933. Disponível em: https://www.hcch.net/pt/about/moreabout-hcch/resolution Acesso em: 02 jul. 2019.

ISRAEL tem protestos por lei de "barriga de aluguel" que exclui homens. Exame, São Paulo, jul. 2018. Disponível em: https://exame.abril.com.br/mundo/ israel-tem-protestos-por-lei-de-barriga-de-aluguel-queexclui-homens/ Acesso em: 20 jun. 2019.

KIRSHNER, Shany Noy. Selling a Miracle? Surrogacy Through International Borders: Exploration of Ukrainian Surrogacy. Journal of International Business and Law, v. 14, n. 1, p. 77-97, jan. 2015.

LANDMEIER, Felipe Redecker; SCHMIDT, Alice Krämer Iorra. A (im)possibilidade jurídica de elaboração de contrato de gestação de substituição. Revista Destaques Acadêmicos, Lajeado-RS, v. 8, n. 2, p. 93-110, 2016.

LOURENZON, Patrícia Miranda. Contrato de Gestação por substituição: proibi-lo ou torná-lo obrigatório? Doutrinas Essenciais Obrigacõoes e Contratos, São Paulo, v. 4, p.1129-1156, jun. 2011.

MÃE de aluguel tinha concordado em ficar com bebê com Down, diz agente. G1, São Paulo, 2014. Disponível em: http://g1.globo.com/mundo/noticia/2014/08/ mae-de-aluguel-concordou-em-ficar-com-bebe-comdown-diz-agente.html Acesso em: 20 jul. 2019.

MOHAPATRA, Seema. Adopting an international convention on surrogacy: a lesson from intercountry adoption. Loyola University Chicago International Law Review, v. 13, n. 1, p. 24-55, 2015.

ORGANIZAÇÃO DAS NAÇÕES UNIDAS. Convenção para a redução do Número de Apatridia. Nova York, 30 ago. 1961. Disponível em: https://www.acnur.org/ fileadmin/Documentos/portugues/BDL/Convencao_ para_a_Reducao_dos_Casos_de_Apatridia_de_1961. pdf Acesso em: 04 fev. 2021. 
ORGANIZAÇÃO DAS NAÇÕES UNIDAS. United Nations tretaty collection: Convention on the Reduction of Statelessness. Disponível em: https://treaties.un.org/ pages $/$ ViewDetails.aspx?src=TREATY\&mtdsg no=V-4\&chapter=5 Acesso em: 05 fev. 2021.

PIERSANTI, Valeria et al. Surrogacy and "Procreative Tourism": what does the future hold from the ethical and legal perspectives? Medicina, v. 57, n. 1, p. 47-63, 2021.

PUEYO, Manuel José M. Maternidad subrogada y prestación de maternidad. Revista del Ministerio de Empleo y Seguridad Social, Madrid, n. 116, p. 21-56, 2015.

RIVABEM, Fernanda S.; GLITZ, Frederico. Bebê globalizado: a gestação de substituição e o direito internacional privado brasileiro. Revista da Faculdade Mineira de Direito, v. 23, n. 46, p. 249-270, 2020.

ROVATI, Lola. El escándalo de BioTexCom, la clínica de maternidad subrogada ucraniana investigada por posible falsedad documental, delito fiscal y tráfico de bebés. Bebés y más, set. 2018. Disponível em: https:// www.bebesymas.com/noticias/escandalo-biotexcomclinica-maternidad-subrogada-ucraniana-investigadaposible-falsedad-documental-delito-fiscal-trafico-bebes Acesso em: 02 jul. 2019.

SANDEL, Michael J. Contra a perfeição: ética na era da engenharia genética. Rio de Janeiro: Civilização Brasileira, 2013.

SARLET, Gabrielle Bezerra S.; ANDRADE, Denise Almeida. A parentalidade corresponsável e a maternidade por sub-rogação: uma análise a partir do enfoque jurídico dos sistemas normativos brasileiro e português. Pensar - Revista de Ciências Jurídicas, v. 25, n. 1, p. 1-15, jan./mar. 2020.

SARLET, Ingo Wolfgang. Dignidade da pessoa humana e direitos fundamentais na Constituição Federal de 1988. Porto Alegre: Livraria do Advogado, 2011.

SARMENTO, Liv Azevedo. A gestação de substituição e seus desafios no Direito Internacional Privado. 2019. Dissertação (Mestrado em Direito) - Universidade de São Paulo, São Paulo, 2019.
SILVA, Flávia Alessandra Naves. Gestação por substituição: direito a ter um filho. Revista de Ciências Jurídicas e Sociais. Guarulhos, v. 1, n. 1, p. 50-67, 2011.

SILVA, Paula Martinho da. A procriação artificial: aspectos jurídicos. Lisboa, Portugal: Moraes, 1986.

SOUZA, Marise Cunha de. As técnicas de reprodução assistida: a barriga de aluguel: a definição da maternidade e paternidade: bioética. Revista da EMERJ, Rio de Janeiro, v. 13, n. 50, 2010.

STARK, Barbara. Transnational surrogacy and international human rights law: transnational surrogacy and international human rights law. ILS A Journal of International \& Comparative Law, v. 18, n. 2, p. 369-386, 2011 2012.

SWENNEN, Frederik. Motherhoods and the Law. In: WILLEKENS, Harry et al. (ed.). Motherhoods and the Law. Göttingen: Universitätsverlag Göttingen, 2019. p. 101118.

TEIXEIRA, Caroline Rocha Pereira. A maternidade de substituição e o conflito de presunção de maternidade certa: estudo de casos. Revista de Doutrina Jurídica, v. 108, n. 1, p. 125-144, 2017.

Torres, Gloria; Shapiro, Anne; Mackey, Tim K. A review of surrogate motherhood regulation in south American countries: pointing to a need for an international legal framework. BMC Pregnancy Childbirth, v. 19, n. 46, p. 1-12, 2019.

Tsfati, Maya et al. Fatherhood as a Spatial-contextual phenomenon: Israeli gay fathers through surrogacy. Men and Masculinities, p.1-21, jan. 2020.

UKRANE. Family Code. 2004. Disponível em: jafbase. fr/docEstEurope/FAMILY_CODE_OF_UKRAINE. pdf Acesso em: 03 mar. 2021.

XAVIER, João Proença. Biomedicina reproductiva e direitos humanos. Revista Ibérica do Direito, v. 1, n. 2, p. 19-28, 2020.

ZENNI, Alessandro Severino V. Os "ruídos" da ciência e o retorno ao direito clássico: única via à dignidade da pessoa humana. Universitas Jus, Brasília, v. 27, n. 3, p. 128-144, 2016. 
Para publicar na Revista de Direito Internacional, acesse o endereço eletrônico www.rdi.uniceub.br ou www.brazilianjournal.org.

Observe as normas de publicação, para facilitar e agilizar o trabalho de edição. 